Check for updates

Cite this: RSC Adv., 2017, 7, 51175

\title{
Functionalized carbon nanotube (CNT) membrane: progress and challenges
}

\author{
Merry Sianipar, ${ }^{a}$ Seung Hyun Kim, ${ }^{\mathrm{b}}$ Khoiruddin, (D) ${ }^{\mathrm{c}}$ Ferry Iskandar (D) ad \\ and I Gede Wenten (1D*ac
}

The role of carbon nanotube (CNT) as filler in a membrane matrix became popular recently. CNT is believed to solve the trade-off issue between permeability and selectivity, and also fouling problems in membrane filtration applications. Their fullerene form is a key point to provide a higher pore size on membrane surface as well as empty space called porosity in membrane structures. However, the hydrophobicity characteristic of CNT has made it difficult to distribute and it tends to agglomerate with each other which leads to a decrease in the dispersion ability in a solvent and, in the same way, a decline in the compatibility of a membrane structure. Functionalization of CNT is expected to solve those problems. Moreover, membrane hydrophilicity, which is provided by the existence of hydrophilic functionalized CNT, is aimed to achieve the anti trade-off between permeability and selectivity based on a electrostatic repulsion concept. By an electrostatic repulsion process, a pollutant will be repelled from attaching to a membrane surface while water will be strongly attracted and be transported through the membrane. Therefore, various approaches have been investigated to functionalize CNT for achieving a high dispersion of CNT as well as high compatibility between CNT and a polymer matrix which lead to improvement of modified membrane properties and performances. This paper reviews the progress of CNT functionalization applied in membrane filtration during the years 2006 up to 2016. The influence of functionalized CNT in improving membrane properties as well as membrane performances is specifically highlighted.

Received 3rd August 2017

Accepted 22nd October 2017

DOI: $10.1039 / c 7 r a 08570 b$

rsc.li/rsc-advances

\section{Introduction}

Membrane technology has already gained increasing attention as a promising alternative for conventional separation technologies in various fields. ${ }^{\mathbf{1 - 4}}$ Membranes have been widely used in water and wastewater treatment, ${ }^{5-10}$ food processing, ${ }^{11-15}$ chemical industry, ${ }^{16,17}$ biotechnology, ${ }^{18-22}$ medical and pharmaceuticals, ${ }^{23,24}$ and energy conversion. ${ }^{25-29}$ Increasing application of membrane technology is due to advantages offered such as more energy efficient, low operating cost, smaller footprint, easy to scale up, and easy operation..$^{30,31}$ In the case of water treatment, reverse osmosis (RO) membranes have become the leading desalination process with about $60 \%$ of the total desalination plants replacing thermal-based desalination technologies. ${ }^{32}$ Nowadays, seawater RO (SWRO) plants can produce freshwater water at $<1$ US\$ per $\mathrm{m}^{3}$ with a significant reduction of

${ }^{a}$ Research Center for Nanosciences and Nanotechnology, Institut Teknologi Bandung, Jalan Ganesha 10, Bandung 40132, Indonesia

${ }^{b}$ Civil Engineering Department, Kyungnam University, 449 Woryeong-dong, Masanhappo-gu, Changwon-si, Gyeongsangnam-do, Republic of Korea

${ }^{c}$ Chemical Engineering Department, Institut Teknologi Bandung (ITB), Jalan Ganesha 10, Bandung 40132, Indonesia. E-mail: igw@che.itb.ac.id

${ }^{d}$ Department of Physics, Institut Teknologi Bandung (ITB), Jalan Ganesha 10, Bandung 40132, Indonesia energy consumption. ${ }^{5}$ Nevertheless, they also have several disadvantages which limits their operations. Synthetic membranes fabricated from conventional materials (polymeric and inorganic) usually face trade-off problems between selectivity and permeability and also a high fouling tendency. ${ }^{30,33-35}$ Progressive studies of membrane modifications have been developed to overcome those disadvantages. Modifications are mostly focused on the addition of nanoparticle as fillers in a membrane matrix including zeolites, ${ }^{36}$ graphene, ${ }^{37,38}$ and other nano-metal oxide particles such as $\mathrm{TiO}_{2},{ }^{39,40} \mathrm{Fe}_{3} \mathrm{O}_{4}{ }^{41}$ $\mathrm{SiO}_{2},{ }^{42,43} \mathrm{Al}_{2} \mathrm{O}_{3},{ }^{44,45}$ and carbon nanotube (CNT). ${ }^{46} \mathrm{CNT}$ has intensively attracted the attention of world research. It has interesting characteristics e.g., high aspect ratio, low density, and high mechanical strength and stiffness. ${ }^{47}$ Their mechanical properties are remarked at approximately 1.2 TPa for Young's modulus and $45 \mathrm{Gpa}$ for tensile strength. ${ }^{48}$ Moreover, CNT has strong $\pi-\pi$ stacking interaction with aromatic compounds which leads to irreversibly adsorbed contact between hydrophobic CNT and aromatic compounds. ${ }^{49}$ These remarkable properties put CNT on top as an effective material in the fabrication of nanocomposite membranes.

The first implementation of CNT as filler in polymer was reported by Ajayan and friends ${ }^{50}$ three years after Iijima first discovered CNT in $1991 .{ }^{51}$ Since then, more researches related 
to CNT implementation have been developed for many kinds of application. However, some hurdles which cannot be prevented with this material include the entanglement of CNT and less dispersibility in solution. A high entanglement of CNT-CNT due to a strong $\pi-\pi$ stacking interaction has resulted in poor interfacial interactions between CNT and a polymer. ${ }^{52}$ Meanwhile, CNT, which has small diameter (nanometer) and high aspect ratio, has been implicated due to its extremely large surface area, as leading to the dispersion problem of CNT in a polymer matrix. ${ }^{53}$ That "less dispersion problem" is also due to the hydrophobic and inert characteristics of CNT. ${ }^{54}$ Some studies revealed that CNT was difficult to disperse in various solvents such as $\mathrm{N}$-methyl-2-pyrrolidone (NMP), $\mathrm{N}, \mathrm{N}$-dimethylacetamide (DMAc), dimethyl sulfoxide (DMSO), and $N, N$ dimethylformamide (DMF) as well as in polymer matrices which tend to cause aggregation of CNT. ${ }^{55,56}$ Unfortunately, this aggregation resulted in inefficient stress transfer to individual nanotubes ${ }^{52}$ and tended to decrease mechanical properties of modified membranes. ${ }^{57}$

Despite the weaknesses of its original characteristics, CNT still prepossess interest from researchers to investigate their applications in membrane preparation; for example, a progressively developed study on CNT functionalization which concentrated on the entanglement and hydrophobicity of membranes in solution. Commonly, approaches are mainly categorized into two types including mechanical and chemical treatment. Mechanical treatment, such as sonication for a certain time, was found to solve the entanglement behavior of CNT in solution. Sonication treatment works based on wave movements that promote the separation of individual nanoparticles from an entanglement. ${ }^{53}$ A sonication process is usually applied when CNT is mixed with solution in order to enhance their distribution. Meanwhile, chemical treatments are usually used to provide hydrophilicity by introducing hydrophilic/functional moieties or macromolecules on a CNT surface. This treatment type will modify the CNT surface, thus making them easily disperse in a solvent solution as well as in polymer matrices. By this means, hydrophilicity known as a "polar characteristic" is developed on a CNT surface. Thus, it would facilitate interface binding between polar CNT and a polar organic solvent. ${ }^{55}$ This functionalized CNT will have a greater affinity for polymer matrices and eventually have efficient thermodynamics wetting with polymer matrices. ${ }^{57}$ Meanwhile, a hydrophilic CNT not only improves the dispersibility of CNT in solvents and polymers but also enriches it with hydrophilic moieties in the membrane. These could produce excellent membrane properties due to higher hydrophilicity, bigger pore size, higher porosity, and rougher/ smoother surface structure. Those excellent membrane properties are followed by remarkable membrane performances such as increased permeability, increased rejection, anti-tradeoff between permeability and selectivity, and antifouling properties on nanocomposite membranes. Both advantages of making CNT hydrophilic to increase their dispersibility and improve modified membrane properties and performances are important objectives of CNT functionalization in membrane filtration applications.
CNT can be designed to have a tube diameter that fits with water molecules which is favorable for desalination. ${ }^{58}$ Therefore, CNT has been increasingly used to improve membrane performance for desalination applications such as reverse osmosis, nanofiltration, forward osmosis, and membrane distillation, because it can enhance water permeability and salt rejection using membranes. ${ }^{58-60}$ This improvement was considered as an effect of the unique structure of CNT and its interaction with water molecules. Furthermore, the increased water permeability resulted in an insignificant change of salt rejection. ${ }^{58}$ This is one attractive feature of CNT-membranes which is preferable to solve the tradeoff problem between permeability and selectivity as encountered in desalination applications. Meanwhile, enhanced water permeability is expected to reduce energy consumption of those membrane-based desalination processes. $^{60}$ CNT membrane preparation, functionalization, applications, challenges, and future perspectives have been reviewed in the literature. ${ }^{6 \mathbf{6 1 6 2}}$ In this paper, the progress of studies related to CNT functionalization approaches, especially when they were applied in the membrane field, is reviewed. The review is based on reports from the last ten years (2006-2016). In addition, the role of functionalized CNT on membrane properties such as membrane porosity, morphology, surface roughness, hydrophilicity, and membrane performances are discussed. Furthermore, the future outlook of functionalized CNT membranes is pointed out.

\section{Progress of CNT functionalization approaches in membrane applications}

CNT applied to membrane preparation was first performed by Choi et al. in 2006. ${ }^{55}$ They functionalized CNT with acid treatment (sulfuric and nitric acid) to introduce carboxylic groups on the CNT surface to overcome a lack of interaction of CNT and an organic solvent as well as a polymer matrix. ${ }^{55}$ Unfortunately, Choi et al. ${ }^{55}$ found the incorporation of carbon nanotubes in the modified membrane matrix was hindered by poor interfacial compatibility of the carbon nanotubes with the polysulfone polymer which leads to unselective voids in a membrane. Furthermore, the development of CNT functionalization was given by Qiu and friends. ${ }^{63}$ They tried to graft isophthaloyl chloride groups on the acid functionalized carbon nanotube's surface through reacting carboxylated carbon nanotubes with 5isocyanato-isophthaloyl chloride (ICIC). The objective was to improve the incompatibility between the polymer and carbon nanotubes as Choi et al. ${ }^{55}$ had faced previously. The attachment of ICIC on acid functionalized CNT occurred without blocking or affecting the pore structure of the carbon nanotubes. However, a less compatibility between CNT and polymer still happened. Wu et al. tried to overcome these incompatibility problems by reacting acid functionalized CNT with TEOA (triethanolamine). ${ }^{64}$ TEOA has provided the compatibility between CNT and brominated polyphenyl oxide (BPPO) as well as the hydrophilicity of the membranes due to its three hydroxyl groups.

Celik et al. in their two reports used acid treatment to provide hydrophilic groups on their CNT surfaces. ${ }^{65,66}$ Acid treatment via 
an oxidation process results in an opened cap and short length CNT. The opened caps will facilitate the conversion of terminal carbon to carboxylic groups. ${ }^{66}$ Meanwhile, the short length of CNT will increase a good dispersion of CNT throughout a polymer matrix. ${ }^{66}$ In general, their concept is quite similar to previous studies. The acid treatment utilized a concentrated acid solution $\left(\mathrm{H}_{2} \mathrm{SO}_{4} / \mathrm{HNO}_{3}\right)$. Interestingly, the mixture solution ratio between $\mathrm{H}_{2} \mathrm{SO}_{4}$ and $\mathrm{HNO}_{3}$ was $1: 3$ which is inversely compared to Choi et al., Qiu et al., and Wu et al. $\left(\mathrm{H}_{2} \mathrm{SO}_{4} / \mathrm{HNO}_{3}=3: 1\right) \cdot{ }^{55,63,64}$ It was pre-assumed that the risk of wall breakage during the acid treatment might be decreased since the acidity of $\mathrm{HNO}_{3}$ is not as strong as $\mathrm{H}_{2} \mathrm{SO}_{4} \cdot{ }^{67}$ Yan et al. mentioned that the acid treatment tends to break down the walls of carbon nanotubes and to harm the mechanical strength of CNT. ${ }^{68}$ Regarding wall breakage, the use of polyethersulfone (PES), which has outstanding mechanical strength, thermal stability, and formability as a polymer matrix, is predicted as a strategy to face that problem. Conclusively, a strong reaction between CNT and PES through hydrogen bonds between sulfonic groups of PES and hydrophilic groups of functionalized CNT improved the compatibility and hydrophilicity of the modified membrane.

Consistent with previous studies, Vatanpour et al. ${ }^{69}$ used acid treatment and introduced another option by adding polyvinyl pyrrolidone (PVP) as an additive in CNT/PES membranes to deal with the wall breakage during an acid treatment ${ }^{65}$ and incompatibility between the acid treated CNT with a certain polymer matrix. ${ }^{55,64}$ PVP is known as a polymer additive which is used to enhance the phase separation of membrane solutions resulting in enlargement of membrane structures. ${ }^{70-72}$ In brief, the addition of PVP additive to a CNT/PES membrane is effective for improving the compatibility of a membrane structure. ${ }^{73}$ Another effective approach after six years from the Choi et al. ${ }^{55}$ report was revealed by Mansourpanah et al. ${ }^{74}$ Polycaprolactone (PCL) was attached to the acid functionalized CNT surface to increase the hydrophilic groups, especially carboxyl groups $(\mathrm{C}=$ O). Using PES as a polymer matrix, they fabricated a CNT nanocomposite membrane with a PVP additive. These combinations are successful in obtaining compatibility and increasing anti-fouling performance of a membrane.

Since the year 2011, interest in CNT modification has progressively developed. Without ignoring the advantage of acid treatment, most researchers still apply acid treatment before further functionalizing a CNT surface. Some researchers recommend functionalization based on polymer attachment either through in situ polymerizations ${ }^{56,75-79}$ or long chain polymer attachment ${ }^{80,81}$ while some researchers suggest amino groups and/or along with another hydrophilic group for comparison ${ }^{\mathbf{8 2 , 8 3}}$ and inorganic materials attachment on a CNT surface. ${ }^{84}$ The rest are still focused on acid treatment only. ${ }^{85-89}$ Various polymer types and additives for membrane support are introduced such as $\mathrm{PVDF}^{\mathbf{8 1 , 8 5 , 8 9}}$ and $\mathrm{PVC}^{\mathbf{8 4}}$ as polymer matrix and PVC as an additive. ${ }^{\mathbf{8 9}}$

Zhao et al., Phao et al., Son et al., and Norouzi et al. are the groups that still apply acid treatment to modify pristine $\mathrm{CNT}^{85-90}$ Majeed et al., Zhao et al., Son et al., Norouzi et al., and Wu et al. used $\mathrm{H}_{2} \mathrm{SO}_{4} / \mathrm{HNO}_{3}$ mixture ${ }^{85,87-90}$ or $\mathrm{HNO}_{3}$ solution, ${ }^{86}$ while Zhao et al. used a $\mathrm{H}_{2} \mathrm{SO}_{4} / \mathrm{H}_{3} \mathrm{PO}_{4}$ mixture to provide hydrophilicity on CNT surfaces. ${ }^{85}$
Daraei et al. treated CNT with some different approaches including attaching polycitric acid (PCA), polyacrylic acid (PAA), and polyacrylamide (PAAm) via in situ polymerization. ${ }^{75}$ The results showed that hydrophilic polymer groups on a CNT surface are successfully provided. Among these three approaches, attaching PCA on CNT showed the best membrane performance. In the same year, Daraei et al. also reported performance improvement of a modified membrane, especially antifouling properties, after embedding PCA functionalized CNT. ${ }^{76}$ Another CNT modification through in situ polymerization was reported by Lee et $a l .{ }^{77}$ They treated oxidized CNT with polyaniline (PANI) polymer. Instead of making CNT hydrophilic, the existence of PANI on the CNT surface is believed to form an electron transfer complex via a donor-acceptor interaction that can generate enhanced electrical and mechanical properties and dispersions of CNT in the polymer matrix. The performance of the CNT/PANI modified membrane for antifouling improvement was the first study. ${ }^{77}$ Different from the Lee et al. ${ }^{77}$ experiments, which applied one type of polymerized functional groups, Yang et al. ${ }^{78}$ tried to combine two remarkable hydrophilic polymer groups, poly (ethylene glycol) methyl ether methacrylate (PEGMA) and methyl triethyl ammonium chloride (PMTAC), in order to obtain optimum membrane properties and performances. PEGMA and PMTAC were generated by surface initiated atom transfer polymerization (SI-ATRP) of polyethylene glycol (PEG) and quaternary ammonium compounds (QAC), respectively. Through embedding PEGMA-CNT and PMTAC-CNT in a membrane matrix, the antifouling properties were improved significantly. ${ }^{78}$

If most polymerized functional groups are negatively charged, Zhang et al. utilized the polymer group poly(sulfobetaine methacrylate) (SBMA) which contained negative and positive charge groups (polyzwitterions). ${ }^{79}$ They believed polyzwitterions possess strong hydration capacity and amazingly anti-adhesion processes for bacteria as well as proteins. Moreover, the positive charge will play role in repelling positively charged metal ions on membrane surfaces. ${ }^{79}$ CNT functionalization based on long chain polymer attachment was reported by Khalid et al. ${ }^{80}$ and Zeng et al. ${ }^{81}$ Khalid et al. introduced dodecylamine (DDA) while Zeng et al. attached aminopropyltriethoxysilane (APTS) polymer on CNT surfaces. These polymer functional groups mainly consist of amide groups $\left(\mathrm{NH}_{2}\right)$. By these movements, they not only facilitate better dispersion and de-bundling of hydrophobic inorganic solvents, but also enhance compatibility and affinity with the polymer matrix support. ${ }^{\mathbf{8 0 , 8 1}}$

Making CNT more hydrophilic by attaching amine or amide groups is performed by Rahimpour et al. and Zarrabi et al. ${ }^{\mathbf{8 2 , 9 1}}$ Amine group is categorized as one of the hydrophilic groups that has high reactivity and is able to react with many chemicals such as polymers. ${ }^{92-94}$ After mixing oxidized CNT with 1,3-phenylenediamine (mPDA) ${ }^{91}$ or 4,4-diamino diphenyl methane (DDM). ${ }^{82} \mathrm{NH}_{2}$ groups are generated on CNT surfaces. They believed $\mathrm{NH}_{2}-\mathrm{CNT}$ would increase hydrophilicity of the modified membrane. ${ }^{8,91}$ Speaking of hydrophilic groups including hydroxyl, carboxylic, and amide groups, Xue et al. compared properties and performances given by these different hydrophilic groups in modified membranes. ${ }^{83}$ Carboxylic groups are generated by acid treatment, while hydroxyl groups are 
produced through hydrothermal treatment. On the other hand, amide groups are created through the reaction between carboxylated CNT with sodium dodecyl $\left(\mathrm{SOCl}_{2}\right)$. Interestingly, among those hydrophilic groups, hydroxyl groups show the best performance, especially for permeability and selectivity, followed by carboxyl and amide groups. ${ }^{\mathbf{8 3}}$

Another important approach is given by Wang et al. and Vatanpour et al. ${ }^{\mathbf{6 9 8 4}}$ The approach is attaching inorganic materials on CNT surfaces. Vatanpour et al. introduced $\mathrm{TiO}_{2}$ on CNT surfaces. ${ }^{69}$ Nanosized titanium dioxide $\left(\mathrm{TiO}_{2}\right)$ was found as a superior additive for polymer membranes because of its high hydrophilicity and good chemical stability. ${ }^{95}$ The addition of $\mathrm{TiO}_{2}$ on an acid-modified CNT surface is performed through a photocatalytic reaction. CNT itself has been reported as a good support material for photocatalytic reactions. ${ }^{96}$ An electron of $\mathrm{TiO}_{2}$ generated during a photo-catalytic reaction would immigrate into the CNT and lead to a decrease of electron hole pairs. ${ }^{97}$ These reduced electron hole pairs are considered to provide more hydrophilic properties throughout CNT walls. $^{69}$ Therefore, coating CNT with $\mathrm{TiO}_{2}$ will enhance the dispersion of them in various organic solvents and polymers ${ }^{68}$ as well as improving the interaction between CNT and the polymer matrix. ${ }^{98}$ Meanwhile, Wang et al. attached $\mathrm{Fe}_{3} \mathrm{O}_{4}$ on CNT surfaces. ${ }^{84}$ Not only indicated as a hydrophilic material, $\mathrm{Fe}_{3} \mathrm{O}_{4}$ is also known as a material which has excellent properties in electrochemistry, magnetic, or adsorption for some special organic molecules. Therefore, the attachment of $\mathrm{Fe}_{3} \mathrm{O}_{4}$ to CNT is aimed to improve antifouling properties of membranes.

Considering the breakage risk of acid-treated CNT, Sianipar et al. suggested applying polydopamine coating via direct polymerization on CNT surfaces. ${ }^{56}$ This was the first study that discussed the role of polydopamine-coated CNT in membranes. Previously, Fei et al. ${ }^{99}$ successfully coated CNT surfaces with polydopamine via a non-covalent interaction. Polydopamine is generated via dopamine self-polymerization to form a thin layer inspired by the composition of adhesive proteins in mussels ${ }^{\mathbf{1 0 0}}$ and is known to be rich in amine and hydroxyl groups. ${ }^{99-105}$ Therefore, a polydopamine coated surface becomes strongly hydrophilic and much more polar. ${ }^{106}$ Moreover, polydopamine film is found to enhance the mechanical properties of coated materials. ${ }^{\mathbf{1 0 6}}$ Finally, they surely predicted that coating MWCNT surfaces with polydopamine will enhance the membrane properties as well as its performances.

Among the reports given after the year 2011, most groups have successfully obtained the improvement of membrane compatibility. ${ }^{56,75-77,82,84,85,87,89,107,108}$ Meanwhile, the rest of the groups still faced incompatibility on their modified membrane. ${ }^{78,81,83,86,88}$

\section{Preparation of functionalized CNT membrane}

\section{Functionalization of CNT}

Methods for preparing functionalized CNT have been reviewed in the literature..$^{5,109-111}$ In summary, the functionalization of CNT can be divided into chemical and physical methods. With chemical functionalization, CNT is chemically bonded with the functional groups. For physical methods, the modifier can be wrapped (polymer wrapping) and adsorbed onto CNT, or stored in the cavity of the CNT. ${ }^{53}$ As previously explained in Section 2, functionalized CNT is used in the membrane to improve the dispersity of CNT and also to improve performance of CNT membranes. For those purposes, CNT has been functionalized with various functional groups such as carboxylic, hydroxyl, amine, polymer, and inorganic compounds (Table 1). In this sub-section, details of functionalization of CNT for preparation of membranes are overviewed.

Acid treatment has been used in several studies to introduce carboxylic groups onto CNT. The introduction of a carboxylic group, which has hydrophilic properties, is intended to improve dispersity of CNT in a polar organic solvent, e.g., NMP, DMF, DMSO, etc. ${ }^{55}$ In an acid treatment, CNT is reacted with a concentrated acid solution such as sulfuric and nitric acid. Typically, the mixtures of the acid are $1 / 3$ or $3 / 1 \mathrm{v} / \mathrm{v}$ of $\mathrm{HNO}_{3} /$ $\mathrm{H}_{2} \mathrm{SO}_{4}$ solution. ${ }^{55,65,73,89}$ Detailed procedures of acid treatment can be found in the literature. In brief, CNT is dispersed in an acid mixture and refluxed at relatively high temperature for a period of time. Subsequently, the CNT is then washed, filtered, and dried. The acid-treated CNT can be used to prepare CNT membranes or can be further treated with chemical treatment to attach other functional groups. Zarrabi et al. used acid treatment as the first step during the preparation of MWCNT$\mathrm{NH}_{2} \cdot{ }^{82}$ The acid mixture was $3 / 1 \mathrm{v} / \mathrm{v}$ of $\mathrm{H}_{2} \mathrm{SO}_{4} / \mathrm{HNO}_{3}$. The acidtreated MWCNT or MWCNT-COOH were then converted into MWCNT-COCl. In the synthesis of MWCNT-COCl, MWCNT$\mathrm{COOH}$ was reacted with $\mathrm{SOCl}_{2}$ and $\mathrm{DMF}$ at $70{ }^{\circ} \mathrm{C}$ for $24 \mathrm{~h}$. The precipitate obtained from the reaction was dried. MWCNT$\mathrm{COCl}$ was then converted into MWCNT- $\mathrm{NH}_{2}$. For this purpose, MWCNT-COCl was dispersed in dichloromethane $\left(\mathrm{CH}_{2} \mathrm{Cl}_{2}\right)$ containing the aromatic diamine of 4,4'-diaminodiphenylmethane (DDM). The reaction was conducted at $90{ }^{\circ} \mathrm{C}$ for $24 \mathrm{~h}$ and the MWCNT- $\mathrm{NH}_{2}$ was produced via an amide linkage.

Acid treatment was also used prior to attachment of other functional groups onto CNT. ${ }^{63,80,81,91}$ For example, Qiu et al. prepared MWCNT with functional groups of 5-isocyanatoisophthaloyl chloride (ICIC) after an acid treatment using a mixed acid solution $\left(\mathrm{H}_{2} \mathrm{SO}_{4}: \mathrm{HNO}_{3}=3: 1\right) .{ }^{63}$ After acid treatment, the MWCNT was reacted with excess ICIC in a reflux device at $50{ }^{\circ} \mathrm{C}$ for $48 \mathrm{~h}$. Khalid et al. synthesized MWCNT/ dodecylamine (MWCNT-DDA) after acid treatment using 49\% $\mathrm{HNO}_{3}{ }^{80}$ The MWCNT was acid treated at $120{ }^{\circ} \mathrm{C}$ for $48 \mathrm{~h}$. Afterward, the acid-treated MWCNT was reacted with DDA at $90{ }^{\circ} \mathrm{C}$ for $5 \mathrm{~h}$. They explained in a reaction scheme that the acid treatment produced carboxylic $(-\mathrm{COOH})$ and hydroxyl $(-\mathrm{OH})$ groups on MWCNT. These groups were then reacted with DDA wherein the $-\mathrm{OH}$ groups were substituted by DDA. Functionalization of MWCNT with 3-aminopropyltriethoxysilane (APTS) after acid treatment was reported by Zeng et al. ${ }^{81}$ Similar to Qiu et al., the acid treatment was conducted using a mixture of sulfuric and nitric acids $\left(\mathrm{H}_{2} \mathrm{SO}_{4}: \mathrm{HNO}_{3}=3: 1\right)$. To functionalize acid-treated MWCNT with APTS, the treated MWCNT was dispersed in APTS solution (by ultrasonic cleaner) wherein $N, N^{\prime}$ dicyclohexylcarbodiimide (DCC) was used as a condensation 
Table 1 Functionalized CNTs and their preparation method

\begin{tabular}{|c|c|}
\hline Modifier & Method \\
\hline Carboxylic & Acid treatment \\
\hline Carboxylic & Acid treatment \\
\hline Carboxylic & Acid treatment \\
\hline Carboxylic & Acid treatment \\
\hline Carboxylic & Plasma oxidation \\
\hline $\begin{array}{l}\text { 5-Isocyanato-isophthaloyl } \\
\text { chloride (ICIC) }\end{array}$ & $\begin{array}{l}\text { Chemical grafting reaction in } \\
\text { strong acid }\end{array}$ \\
\hline Dodecylamine (DDA) & Chemical grafting \\
\hline Polycaprolactone (PCL) & In situ polymerization \\
\hline Polyacrylic acid (PAA) & In situ polymerization \\
\hline Polydopamine (Pdop) & In situ polymerization \\
\hline Polyaniline (PANI) & In situ polymerization \\
\hline $\begin{array}{l}\text { Polymethyl triethyl ammonium } \\
\text { chloride (PMTAC) }\end{array}$ & $\begin{array}{l}\text { Surface initiated atom transfer } \\
\text { polymerization (SI-ATRP) }\end{array}$ \\
\hline $\begin{array}{l}\text { Poly(ethylene glycol)methyl ether } \\
\text { methacrylate (PEGMA) }\end{array}$ & $\begin{array}{l}\text { Surface initiated atom transfer } \\
\text { polymerization (SI-ATRP) }\end{array}$ \\
\hline $\begin{array}{l}\text { Polysulfobetaine methacrylate } \\
\text { (PSBMA) }\end{array}$ & $\begin{array}{l}\text { Precipitation polymerization } \\
\text { method }\end{array}$ \\
\hline
\end{tabular}

3-Aminopropyl triethoxysilane (APTS)

$-\mathrm{NH}_{2}$

1,3-Phenylenediamine (mPDA)

$-\mathrm{NH}$

$-\mathrm{OH}$

Zwitterionic functional groups

$\mathrm{TiO}_{2}$
Acid treatment

Chemical grafting reaction in

Chemical grafting

In situ polymerization

Chemical grafting

Amination

Hydrothermal treatment

$-$

Precipitation of $\mathrm{TiCl}_{4}$ precursor on the acid treated MWCNT
Procedure

Ref.

$\mathrm{HNO}_{3} / \mathrm{H}_{2} \mathrm{SO}_{4}=3 / 1$

55

$\mathrm{HNO}_{3} / \mathrm{H}_{2} \mathrm{SO}_{4}=3 / 1$

$\mathrm{HNO}_{3} / \mathrm{H}_{2} \mathrm{SO}_{4}=1 / 3$

$\mathrm{HNO}_{3} / \mathrm{H}_{2} \mathrm{SO}_{4}=1 / 3$

Vertically aligned CNT membrane was plasma treated

in $\mathrm{H}_{2} \mathrm{O}$ plasma oxidation

Acid treatment: $\mathrm{HNO}_{3} / \mathrm{H}_{2} \mathrm{SO}_{4}=1 / 3$; at $80{ }^{\circ} \mathrm{C}$ and $4 \mathrm{~h}$

Grafting: functionalized MWCNT + ICIC; at $50{ }^{\circ} \mathrm{C}$ and $48 \mathrm{~h}$

Acid treatment: $69 \%$ of $\mathrm{HNO}_{3}$; at $120^{\circ} \mathrm{C}$ and $48 \mathrm{~h}$

Grafting: functionalized MWCNT + DDA; at $90^{\circ} \mathrm{C}$ and 5 $\mathrm{h}$

Opening of MWCNT : acid treatment, $\mathrm{HNO}_{3} / \mathrm{H}_{2} \mathrm{SO}_{4}=$ $1 / 3$

Filling: opened MWCNT $+\mathrm{AgNO}_{3}$ solution (in water/ ethanol)

Polymerization: filled MWCNT $+\varepsilon$-caprolactone

MWCNT + acrylic acid (monomer) + potassium

persulfate (initiator) + ethylene glycol (cross-linker); at $90{ }^{\circ} \mathrm{C}$ and $4 \mathrm{~h}$

MWCNT + tris- $\mathrm{C}_{4} \mathrm{H}_{11} \mathrm{NO}_{3}+$ dopamine- $\mathrm{HCl}$ solution; at room temperature and $16 \mathrm{~h}$

MWCNT + monomer: aniline + oxidant: ammonium peroxidisulfate in $\mathrm{HCl}$; at $4{ }^{\circ} \mathrm{C}$ and $48 \mathrm{~h}$

Synthesis of CNT-Br from CNT-OH

SI-ATRP of CNT-Br and MTAC

Synthesis of CNT-Br from CNT-OH

SI-ATRP of CNT-Br and EGMA

Grafting $\mathrm{CNT}$ with $\mathrm{C}=\mathrm{C}$ bonds: $\mathrm{CNT}+3$-(methacryloxy) propyl trimethoxysilane (MPS), in ethanol; at $50{ }^{\circ} \mathrm{C}$ and $48 \mathrm{~h}$

Polymerization: functionalized CNT + SBMA +

methacrylic acid (MAA) + ethylene glycol

dimethacrylate (EGDMA)

Acid treatment: $\mathrm{HNO}_{3} / \mathrm{H}_{2} \mathrm{SO}_{4}=1 / 3$

Grafting: acid treated MWCNT + APTS + N, $N^{\prime}-$

dicyclohexylcarbodiimide (condensation agent); at

$70{ }^{\circ} \mathrm{C}$ and $12 \mathrm{~h}$

Acid treatment: $\mathrm{HNO}_{3} / \mathrm{H}_{2} \mathrm{SO}_{4}=1 / 3$

Synthesis of MWCNT-COCl: acid treated MWCNT + $\mathrm{SOCl}_{2}+\mathrm{DMF}$

Synthesis MWCNT- $\mathrm{NH}_{2}$ : MWCNT-COCl + 4,4'-

diamino diphenyl methane in $\mathrm{CH}_{2} \mathrm{Cl}_{2}$

Acid treatment: $\mathrm{HNO}_{3} / \mathrm{H}_{2} \mathrm{SO}_{4}=1 / 3$

Amine functionalized MWCNT: MWCNT-COOH + mPDA in DMF; at $70{ }^{\circ} \mathrm{C}$ and $96 \mathrm{~h}$

Drying of resulted powder

Acid treatment: $\mathrm{HNO}_{3} / \mathrm{H}_{2} \mathrm{SO}_{4}=1 / 3$

Conversion of carboxyl into acyl chloride: MWCNT-

$\mathrm{COOH}+\mathrm{SOCl}_{2}$; at $60{ }^{\circ} \mathrm{C}$ and $12 \mathrm{~h}$

Synthesis MWCNT-NH: MWCNT-acyl chloride +

piperazine in DMF; at $80^{\circ} \mathrm{C} 1$ day

MWCNT + $\mathrm{NaOH}(2 \mathrm{~N})$; at $180{ }^{\circ} \mathrm{C}, 2 \mathrm{~h}$

Acetylation: SWNT-COOH $+\mathrm{SOCl}_{2}$; at $65{ }^{\circ} \mathrm{C}$ and $36 \mathrm{~h}$

Esterification: acetylated SWNT + 3-dimethylamino-1propanol, $\left(\mathrm{CH}_{3}\right)_{2}-\mathrm{N}-\mathrm{C}_{3} \mathrm{H}_{6}-\mathrm{OH}$

Acid treatment: $\mathrm{HNO}_{3} / \mathrm{H}_{2} \mathrm{SO}_{4}=1 / 3$

Grafting: acid treated MWCNT + monohydrated citric acid to produce polycitric acid grafted MWCNT

Coating: grafted MWCNT $+\mathrm{TiCl}_{4}$ 
Table 1 (Contd.)

\begin{tabular}{|c|c|c|c|}
\hline Modifier & Method & Procedure & Ref. \\
\hline $\mathrm{Fe}_{3} \mathrm{O}_{4}$ & Hydrothermal treatment & $\begin{array}{l}\text { Acid treatment: } \mathrm{HNO}_{3} / \mathrm{H}_{2} \mathrm{SO}_{4}=1 / 3 \text {; at } 65{ }^{\circ} \mathrm{C} \text { and } 4 \mathrm{~h} \\
\text { Hydrothermal treatment: acid treated MWCNT }+\mathrm{FeCl}_{3} / \\
\mathrm{FeSO}_{4}(2 / 1)+\text { deionized water; at } 50{ }^{\circ} \mathrm{C} \text { and } 0.5 \mathrm{~h} \\
\text { Continued stirring; at } 65{ }^{\circ} \mathrm{C}, 1 \mathrm{~h} \text {, and pH } 12\end{array}$ & 84 \\
\hline $\begin{array}{l}\text { Poly(allylamine hydrochloride) } \\
\text { (PAH) }\end{array}$ & Chemical wrapping & $\begin{array}{l}\text { Dispersing MWCNT in PAH salty solution }(0.5 \mathrm{M} \mathrm{NaCl}) \\
\text { Heat treatment }\left(80^{\circ} \mathrm{C}\right) \text { and ultrasonication }\end{array}$ & 114 \\
\hline
\end{tabular}

agent. The solution was then stirred at $70{ }^{\circ} \mathrm{C}$ for $12 \mathrm{~h}$. The functionalized MWCNT was obtained after centrifugation, filtration, and drying.

Functionalizations are also conducted by in situ polymerization of monomer onto CNT. ${ }^{56,75,77,78}$ Daraei et al. functionalized CNT with poly(acrylic acid) or PAA via thermal in situ polymerization of acrylic acid aqueous solution containing initiator (KPS) and cross-linker agent (ethylene glycol) $\cdot{ }^{75} \mathrm{MWCNT}$ was dispersed in aqueous solution containing acrylic acid, ethylene glycol, and KPS and the mixture was sonicated. The polymerization reaction was conducted at $90{ }^{\circ} \mathrm{C}$ for $4 \mathrm{~h}$. Lee et al. used in situ polymerization to modify MWCNT with polyaniline. ${ }^{77}$ Similar to the work done by Daraei et al., ${ }^{75}$ the unmodified MWCNT was directly involved in a polymerization reaction wherein the MWCNT was dispersed in the polymerization reactants. Yang et al. reported functionalization of CNT using a surface initiated atom transfer polymerization method or SI-ATRP. ${ }^{78}$ The method was used to attach polymethyl triethyl ammonium chloride (PMTAC) and poly(ethylene glycol) methyl ether methacrylate (PEGMA). The CNT was functionalized in two steps, i.e., synthesis of macroinitiator CNT-Br from CNT-OH and synthesis of CNT-PMTAC and CNT-PEGMA. For synthesis of CNT-Br, commercial CNT$\mathrm{OH}$ (CNT with -OH functional groups) was dispersed in chloroform and the mixture was ultrasonicated. N,N-Dimethylaminopyridine and trimethylamine were added to the mixture while 2bromo-2-methylpropionyl bromide (BiBB) was added drop-wisely at $0{ }^{\circ} \mathrm{C}$. Then, the reaction was carried out at $25{ }^{\circ} \mathrm{C}$ for $48 \mathrm{~h}$. In the second step, CNT-Br was reacted with monomer (EGMA for CNT-PEGMA and MTAC for CNT-PMTAC) in the presence of $N, N, N^{\prime}, N^{\prime \prime}, N^{\prime \prime}$-pentamethyldiethylenetriamine (PMDETA), dimethylsulfoxide, and $\mathrm{CuBr}$ at $70^{\circ} \mathrm{C}$.

Duan et al. ${ }^{112}$ synthesized CNT-PANI using electrochemical polymerization. A polymerization solution was prepared by adding aniline to a $0.5 \mathrm{M}$ aqueous solution of sulfuric/hydrochloric/ oxalic acid. CNT suspension was then deposited on a membrane. A membrane with deposited CNT was immersed in the polymerization solution and connected with an external power source. In this case, the CNT network was used as an anode while a titanium wire was used as cathode. The electropolymerization reaction was conducted by supplying a constant current for $1 \mathrm{~h}$. By using this method, CNT-PANI was produced.

Besides the attachment of carboxylic, hydroxyl, polymer, and other hydrophilic groups, attachment of inorganic compounds such as $\mathrm{TiO}_{2}$ and $\mathrm{Fe}_{3} \mathrm{O}_{4}$ on CNT have been reported. ${ }^{69,84}$
Vatanpour et al. ${ }^{69}$ prepared $\mathrm{MWCNT}-\mathrm{TiO}_{2}$ via precipitation of $\mathrm{TiCl}_{4}$ precursor on the acid treated MWCNT. In their work, an acid mixture of $\mathrm{H}_{2} \mathrm{SO}_{4} / \mathrm{HNO}_{3}$ (3/1) was used in the acid treatment step. The acid-treated MWCNT was then functionalized with monohydrate citric acid. The synthesis of MWCNT-polycitric was aimed to get a better deposition of $\mathrm{TiO}_{2}$ on the CNT. In the final step, $\mathrm{TiO}_{2}$ nanoparticles were coated on MWCNTpolycitric acid. Coating was conducted by dispersing both functionalized CNT and $\mathrm{TiCl}_{4}\left(\right.$ as $\mathrm{TiO}_{2}$ precursor) into $1 \mathrm{M} \mathrm{HCl}$ solution at room temperature then ammonia solution was added. The product was washed and dried. To obtain the MWCNT- $\mathrm{TiO}_{2}$, the product was heated at $500{ }^{\circ} \mathrm{C}$ for $100 \mathrm{~min}$. This step removes polycitric acid and produces the $\mathrm{TiO}_{2}$ deposit. Wang et al. ${ }^{84}$ prepared $\mathrm{MWCNT} / \mathrm{Fe}_{3} \mathrm{O}_{4}$ using a hydrothermal method. Prior to $\mathrm{Fe}_{3} \mathrm{O}_{4}$ attachment, the CNT was acidtreated with an acid mixture of $\mathrm{H}_{2} \mathrm{SO}_{4} / \mathrm{HNO}_{3}$ (3/1) for $4 \mathrm{~h}$ at $65{ }^{\circ} \mathrm{C}$. The acid-treated MWCNT was then mixed with $\mathrm{FeCl}_{3}$ and $\mathrm{FeSO}_{4}$ (molar ratio $2: 1$ ) and ultrasonicated. The mixture was then stirred at $50{ }^{\circ} \mathrm{C}$ for $0.5 \mathrm{~h}$ and furthered stirred at $65{ }^{\circ} \mathrm{C}$ for $1 \mathrm{~h}$ under $\mathrm{pH} 12$. The MWCNT/ $/ \mathrm{Fe}_{3} \mathrm{O}_{4}$ was obtained as precipitate. Hydrothermal treatment was used by Xue et al. to prepare MWCNT-OH. ${ }^{83}$ MWCNT was dispersed in an aqueous solution of $\mathrm{KOH}(2 \mathrm{M})$. To obtain a better dispersion, the mixture was ultrasonicated for $1 \mathrm{~h}$. In the hydrothermal synthesis, the mixture was then heated at $180^{\circ} \mathrm{C}$ for $2 \mathrm{~h}$. The MWCNT-OH was obtained after purification.

Chan et al. functionalized single-walled CNT (SWCNT) with zwitterionic functional groups. ${ }^{113}$ The functionalization was comprised of two steps. In the first step, SWCNT-COOH was reacted with thionyl chloride $\left(\mathrm{SOCl}_{2}\right)$ to produce acetylated SWCNT. In the second step, the acetylated SWCNT underwent esterification using 3-dimethylamino-1-propanol, $\left(\mathrm{CH}_{3}\right)_{2}-\mathrm{N}-$ $\mathrm{CC}_{3} \mathrm{H}_{6}-\mathrm{OH}$. As the result, the functionalized SWCNT has attached positive (tertiary amine group) and negative charges (carboxylated group).

A different approach was used by Amirilargani et al. to functionalize CNT. ${ }^{114}$ They modified MWCNT by wrapping PAH on the MWCNT surface. MWCNT was synthesized via chemical vapor deposition. The home-made MWCNT was modified by dispersing into poly(allylamine hydrochloride) (PAH) salty solution. The PAH salty solution contained $0.5 \mathrm{M} \mathrm{NaCl}$. This mixture was then ultrasonicated, heated at $80{ }^{\circ} \mathrm{C}$, and ultrasonicated again. Characterization of the product confirmed that PAH was wrapped on the CNT. 
Functionalization of CNT may also be conducted after membrane fabrication. This is typically performed on vertically aligned CNT. Unlike mixed-matrix membranes which aim to improve dispersibility of CNT in membrane solution and matrix, functionalization of a vertically aligned CNT membrane is primarily aimed to improve interaction of a membrane with species transported through it. For example, in a study reported by Majumder et al., ${ }^{115}$ fabricated vertically aligned CNT membrane which was plasma oxidized to introduce carboxylic groups. The carboxylated CNT membrane was further modified using other functional molecules including alkanes, dye molecules with negative charge, amine groups, etc. via chemical reactions.

\section{Preparation of CNT membrane}

Generally, a CNT membrane is prepared into vertically aligned and mixed matrix membranes. ${ }^{62,116}$ For a vertically aligned CNT membrane, the CNT was arranged perpendicularly on the support layer (Fig. 1a). Several studies on preparation of
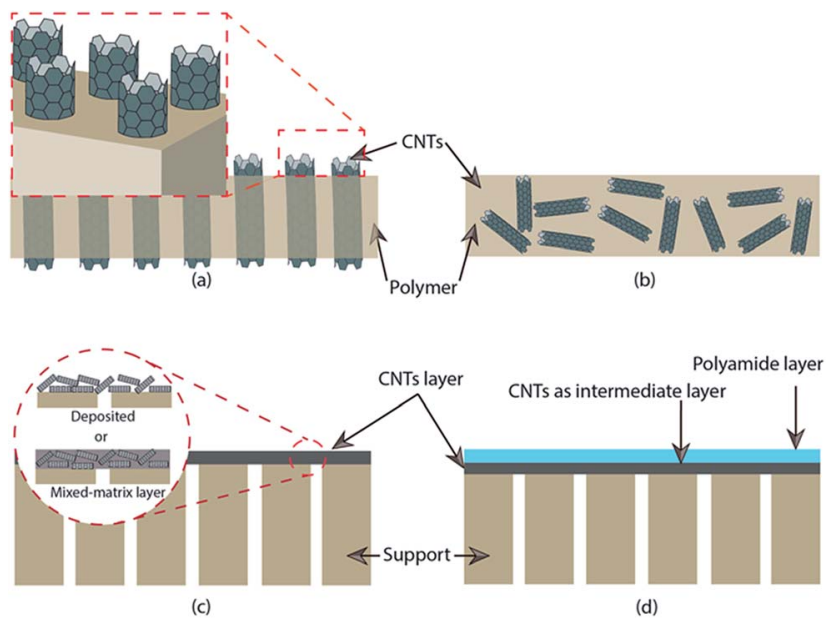

Fig. 1 CNT membranes with various structures. (a) Vertically aligned CNT membrane, (b) mixed-matrix CNT membrane, (c) CNTs are coated on membrane surface or support, (d) CNTs are coated on membrane surface (support) as intermediate layer. vertically aligned CNT membranes are tabulated in Table 2 . One of the most important features of a vertically aligned CNT membrane is a "superfast water transport" through the inner diameter of CNT. ${ }^{116}$ An example of a vertically aligned CNT membrane preparation has been reported by Hinds et al. ${ }^{117}$ In their work, MWCNT was grown on quartz substrate via a chemical vapor deposition process using ferrocene-xyleneargon-hydrogen feed at $700{ }^{\circ} \mathrm{C}$. A solution of polystyrene (PS) in toluene was spin-coated on the surface of MWCNT and then dried in vacuum. MWCNT/PS composite was removed from the quartz by using hydrofluoric acid. To open MWCNT and to remove the excess polymer on the top surface, the film was oxidized using $\mathrm{H}_{2} \mathrm{O}$-plasma oxidation. The synthesized CNT membrane has a tortuosity of 1.1 , mean pore diameter of $7.5 \mathrm{~nm}$, and membrane thickness of $5 \mu \mathrm{m}$. It is worth mentioning that besides the pore diameter, tortuosity of CNT is also an important factor determining the transport of species through cylindrical pores. As in the Hagen-Poiseuille equation, flux is inversely proportional to the tortuosity factor $\left(J \approx \tau^{-1}\right) .{ }^{118}$ Therefore, it is desired to synthesized vertically CNT with a tortuosity factor close to unity because in a vertically aligned CNT membrane, components are transported through the inner walls of the CNT.

Another example of vertically aligned CNT membrane preparation was reported by Choi et al. ${ }^{119}$ They used microwave plasma-enhanced chemical vapor deposition to fabricate a CNT membrane on Ni thin film. They found that diameter, growth rate, and density of CNT could be controlled by adjusting the grain size of Ni thin films. Majumder et al. prepared vertically aligned CNT membranes which were functionalized with various functional groups. ${ }^{115}$ They found that functionalization could improve the selectivity of a CNT membrane. Functionalization also affected the effective pore entrance (inner diameter) of the CNT. The effects of functionalization of vertically aligned CNT membranes have been investigated by Corry via molecular dynamic simulations. ${ }^{120}$ Functional groups were attached at the entrance of CNT pores. Results showed that functionalization could improve salt rejection of a membrane. However, functionalized CNT membranes exhibited lower water flux than an unfunctionalized CNT membrane. Li et al. ${ }^{\mathbf{1 2 1}}$ synthesized vertically aligned MWCNT membranes in a PES matrix and

Table 2 Vertically aligned CNT membranes ${ }^{a}$

\begin{tabular}{|c|c|c|c|c|c|c|}
\hline Structure & Support/matrix & Preparation of MWCNT & $\mathrm{ID} / \mathrm{OD}(\mathrm{nm})$ & $\begin{array}{l}\text { Thickness of } \\
\text { CNT layer }(\mu \mathrm{m})\end{array}$ & Tortuosity & Ref. \\
\hline MWCNT & PS matrix & CVD & 7.5/NA & 5 & 1.1 & 117 \\
\hline MWCNT & Silicon nitride & CVD & $66 / \sim 300$ & 10 & - & 122 \\
\hline MWCNT/nonylamine & PS matrix & CVD + functionalization & $3.7 / \mathrm{NA}$ & 5 & - & 115 \\
\hline MWCNT/kemamine & PS matrix & CVD + functionalization & $5 / \mathrm{NA}$ & 5 & - & 115 \\
\hline MWCNT/polypeptide & PS matrix & CVD + functionalization & 3.3/NA & 5 & - & 115 \\
\hline DWCNT & Silicon nitride & CVD & $1.6 / 2.3$ & 5 & - & 123 \\
\hline MWCNT & Porous alumina & CVD & $6.3 / 20$ & $\sim 10$ & 1.26 & 124 \\
\hline DWCNT & Epoxy & CVD & 10 & $\sim 4000$ & - & 125 \\
\hline MWCNT & PES matrix & CVD & $\mathrm{NA} / 15$ & 130 & - & 121 \\
\hline
\end{tabular}

${ }^{a}$ CVD - chemical vapour deposition process; DWCNT - double-walled CNT; PES - polyethersulfone; PS - polystyrene. 
compared them to mixed-matrix MWCNT/PES and bare PES membranes. The vertically aligned MWCNT membrane has 3 times and more than 10 times water flux than the MWCNT/PES and PES membranes, respectively. Despite the excellent water permeability, preparation of vertically aligned CNT membranes is very complicated; thus, many researches are directed to preparing mixed-matrix CNT membranes. ${ }^{116}$

In a mixed matrix CNT membrane, CNT is dispersed in a membrane casting solution which is then cast in a flat sheet membrane (Fig. 1b). In this case, the membrane has irregular alignment of CNT. Mixed matrix membranes containing CNT can be prepared by the phase inversion process and solution casting method. Compatibility between CNT and a polymer matrix is an important factor for obtaining membranes with good performance and mechanical stability. Wu et al. ${ }^{64}$ prepared a mixed-matrix ultrafiltration membrane containing MWCNT with carboxylic groups. To obtain a better compatibility between MWCNT and the polymer matrix, they used a cross-linking agent. Triethanolamine (TEOA) was used to cross-link MWCNT with brominated polyphenylene oxide (BPPO) during the preparation of a membrane. A casting solution containing BPPO, solvent, TEOA-solvent, and MWCNT$\mathrm{COOH}$ was stirred and ultrasonicated and the casting solution was then cast into a membrane. They reported that the prepared membrane contained quaternary ammonium groups (positive charge) and carboxylic groups. The BPPO-TEOA-MWCNT membrane showed high hydrophilicity, permeability, chemical stability, and excellent separation performance. A non-solvent induced phase inversion (NIPS) method was used by Zhang et al. to fabricate a mixed matrix PES/CNT-SBMA ultrafiltration membrane. $^{79}$ In their work, DMF was used as solvent while water was used as non-solvent in a coagulation bath. The membrane solution contained PES, CNT-SBMA, DMF, and PEG2000 (as a pore-forming agent). After the solution was optically homogeneous and gas bubbles were removed, the solution was then cast onto a glass plate and then immersed in a coagulation bath to remove the solvent.

Yang et al. used spin coating to prepare an ultrafiltration membrane containing CNT-PMTAC and CNT-PEGMA. ${ }^{78}$ In this technique, CNT was dispersed in a solvent and the polymer was added subsequently. Ultrasonication was used to induce a better dispersion. After stirring the mixture, the solution was spin coated onto a glass plate. The thickness of the membrane can be controlled by adjusting the spinning rate.

The functionalized CNT can also be incorporated onto the membrane surface. For example, Zeng et al. used a filtration method to attach MWCNT-APTS onto a microfiltration membrane. ${ }^{81}$ In this method, the functionalized CNT was dispersed in deionized water. The suspension contained 0.01$0.1 \%$ wt of CNT. The suspension was filtered using the membrane (average pore size $0.2 \mu \mathrm{m}$ ) until the permeate was obtained. The results of the study indicated that the functionalized CNT was successfully embedded on the membrane surface (Fig. 1c). The membrane containing CNT is able to reject $\mathrm{Cu}^{2+}$ in the feed solution.

Zarrabi and coworkers used MWCNT- $\mathrm{NH}_{2}$ to modify a nanofiltration membrane and to improve hydrophilicity and separation performance of the membrane. ${ }^{82}$ In this purpose, the functionalized CNT was embedded in the polyamide layer of the NF membrane. The CNT was dispersed into piperazine monomer solution ( 0.001 to $0.01 \mathrm{wt} \%$ of MWCNT- $\mathrm{NH}_{2}$ in piperazine solution) before interfacial polymerization. Results showed that the CNT was successfully embedded in the polyamide layer. The modified membranes have high surface hydrophilicity and smoothness and also showed an improved separation performance. In addition, the modified membrane exhibited an antifouling property. A similar strategy was applied by Xue et al. to introduce functionalized CNT into a NF membrane. ${ }^{83}$ Aqueous piperazine solution containing $1 \mathrm{wt} \%$ of functionalized CNT (MWCNT-COOH, MWCNT-OH, or MWCNT-NH) was cast on polysulfone UF membrane. The coated membrane was then immersed into an organic solution for interfacial polymerization.

Wu et al. fabricated a NF/MWCNT membrane wherein the CNT was deposited on a microfiltration (MF) membrane (as support), which is used as an intermediate layer between the support and polyamide skin layer ${ }^{88}$ (Fig. 1d). Before interfacial polymerization, the CNT was embedded on the MF membrane surface by using vacuum filtration of a CNT suspension. They found that the thickness of the active layer was increased with an increase of CNT layer which associated with the absorbed monomer on the coated membrane. Chan et al. used vacuum filtration during the deposition of a CNT suspension onto a membrane support. ${ }^{113}$ Vacuum filtration was not only used to remove solvent from the suspension but also to provide some alignment to the CNT.

\section{The role of functionalized CNT in influencing the membrane properties}

The approaches of CNT functionalization have been developed year to year in order to provide a good reaction between CNT and organic solvents as well as polymer solutions. Thus, the strong reaction between functionalized CNT and polymer matrix will lead to generation of a nanocomposite membranes with remarkable properties. In this section, how functionalized CNT plays their role in influencing membrane properties are explained in detail. The scheme of functionalized CNT roles in influencing membrane properties is shown in Fig. 2.

Generally, the addition of functionalized CNT has influenced rheological properties as well as chemical characteristics of modified membranes. Rheological properties or physical characteristics represent pore size, porosity, and roughness/ smoothness of modified membranes. The trend shows that the addition of CNT has changed rheological properties indicated by a bigger surface pore size, a higher porosity, and rougher/ smoother membrane structures. A rougher or smoother structure depends on the dose ratio of CNT given by groups. The change in rheological properties of a modified membrane also has provided the morphology type called a macrovoids or nodular structures or finger like pores or free volume characteristics of modified membranes. Meanwhile, one chemical characteristic of modified membranes is recognized as hydrophilicity. To quantify hydrophilicity improvement obtained by addition of 


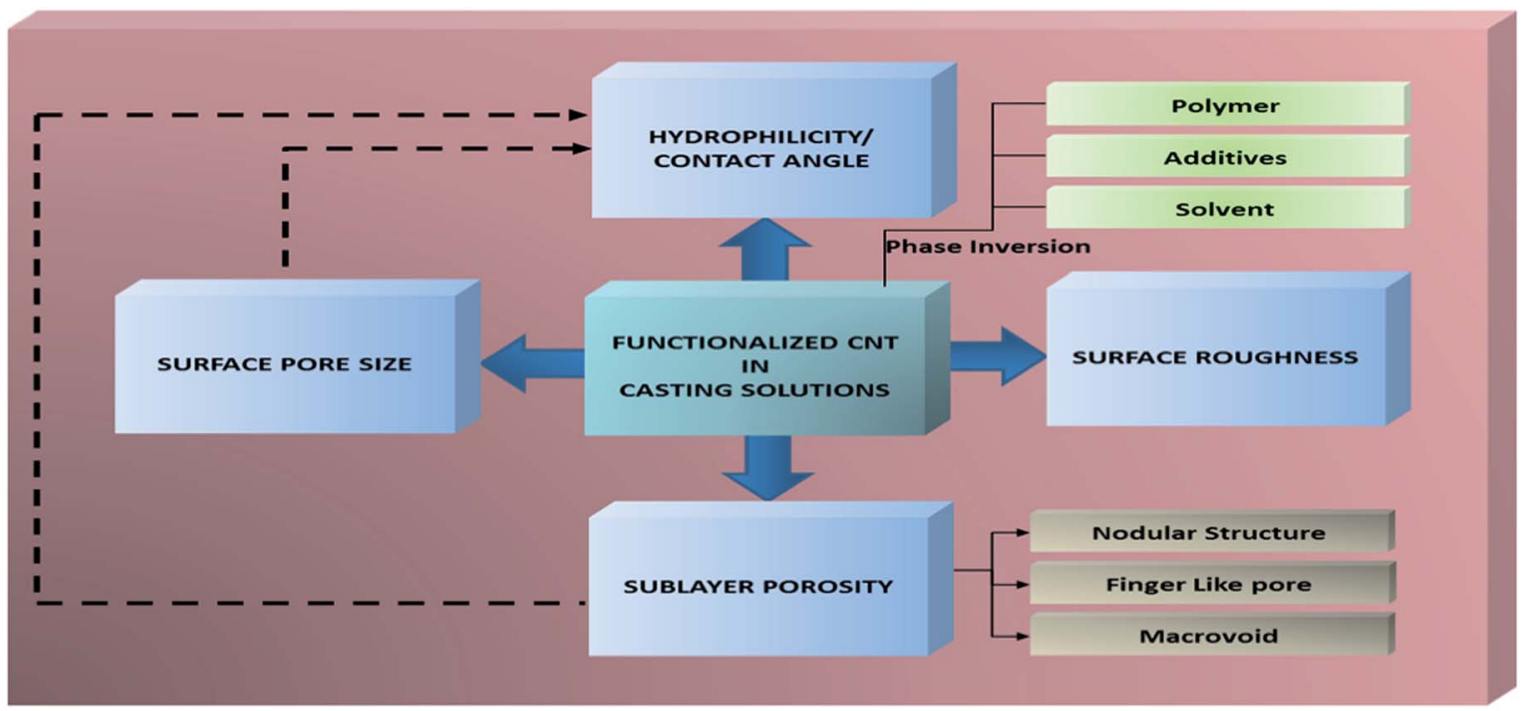

Fig. 2 Scheme of functionalized CNT playing roles in influencing membrane properties.

functionalized/hydrophilic CNT into a membrane, contact angle analysis is generally used. Improved hydrophilicity is observed by a lower contact angle degree. The decrease of contact angle of a modified membrane in the same way is affected by a higher surface pore size as well as porosity of it. More details about improvement of membrane properties from the role of functionalized CNT will be discussed in the next subsections.

\section{The dispersion ability of functionalized CNT}

Dispersion of CNT in a solvent and polymer matrix of a membrane is one important aspect in preparation of CNT membranes, especially for mixed-matrix or composite membranes. One of the purposes of making CNT hydrophilic through various kinds of functionalization is to give rise to a well-dispersed ability of CNT in aqueous solution, especially in organic solvents and polymer solutions. The hydrophobic characteristic of CNT as well as the strong $\pi-\pi$ stacking interaction of CNT-CNT has made them have low solubility in aqueous solutions and extremely easy to agglomerate or entangle each other. ${ }^{52,55}$ These conditions lead to less dispersibility of CNT in these solutions. Through functionalization, hydrophilic/functional moieties or macromolecules are introduced on CNT surfaces leading to the easy dispersion of functionalized CNT in various solutions.

From reviewed reports it can be summarized that the type of solvents used in order to prepare nanocomposite membranes were $N$-methyl-2-pyrrolidone (NMP), dimethyl sulfoxide (DMSO), $N, N$-dimethylformamide (DMF), or $N, N$-dimethylacetamide (DMAc) which are recognized as polar organic solvents. ${ }^{126}$ Choi et al. revealed that functionalized CNT resulted in better dispersion in polar organic solvents including NMP, DMSO, DMF, and DMAc compared with pristine CNT. ${ }^{55}$ Dispersion ability is indicated by a higher absorption number given by UV/visible spectrophotometry analysis. The higher the absorption number is the higher CNT suspension is. The interaction between functionalized CNT and an organic solvent is based on hydrogen bonding which is facilitated by hydrophilic groups on the CNT surface and moieties/molecules groups of organic solvents ${ }^{55}$ (Fig. 3). Some reports also called it polar-polar interaction between hydrophilic CNT and polar solvents. ${ }^{39,56,64,65,73,74}$ Chen et al. and Sendner et al. mentioned that a hydrophilic nature of molecules/moieties is closely related to a polarity characteristic given by those molecules, and vice versa. ${ }^{127,128}$

The interaction between a hydrophilic CNT and polymer also is due to hydrogen bonding. Majeed et al. stated that the interaction of functionalized CNT and a PAN polymer is based on hydrogen bonding between $\mathrm{OH}^{-}$and $\mathrm{C}=\mathrm{N}(\mathrm{CH}-\pi$ interaction $)^{90}$ (Fig. 4a). Meanwhile, a solid nanocomposite polysulfone membrane is generated via hydrogen bonding interactions between the sulfonic groups of PES and the carboxylic groups of functionalized $\mathrm{CNT}^{65}$ (Fig. $4 \mathrm{~b}$ ). The dispersion quality of nanomaterial CNT in the polymer can be identified through viscosity ${ }^{129}$ (Fig. 4c). A good dispersion of CNT in polymer is indicated by an increase of solution viscosity since the nanoparticles act as physical barrier that will slow down coalescence and reduce the domain size of polymer blends. ${ }^{39,55,56,69,130}$

It was shown from several studies that the strategy of making CNT hydrophilic is aimed to promote the transformation of

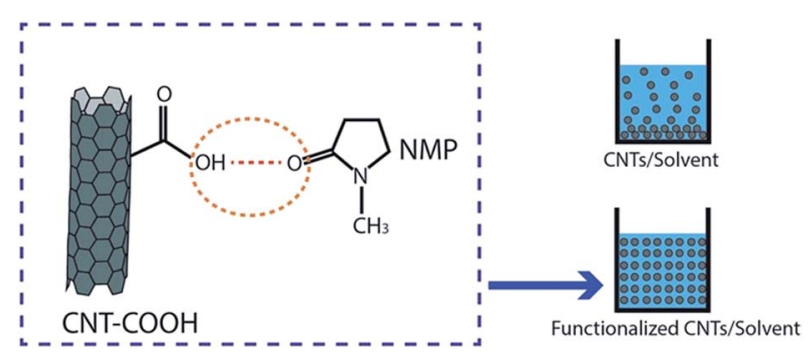

Fig. 3 Example of hydrogen bonding between functionalized CNT and solvent and the dispersion of functionalized CNT in the solvent. 


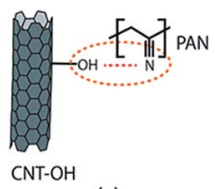

(a)

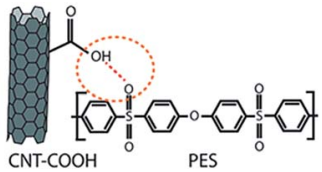

(b)

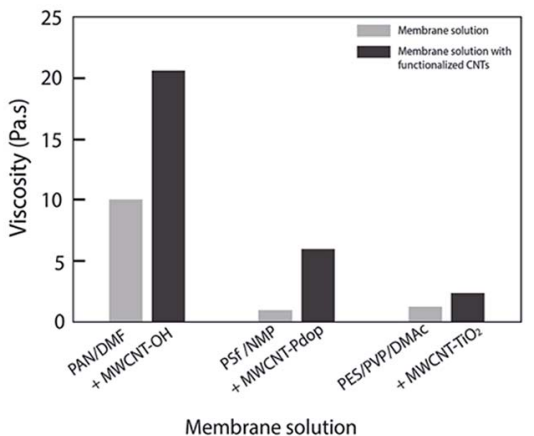

(c)

Fig. 4 Hydrogen bonding of functionalized CNT/polymer matrix and its effect on membrane solution viscosity. (a) CNT-OH/PAN, (b) CNT$\mathrm{COOH} / \mathrm{PES}$, (c) solution viscosity of membrane solution and membrane solution containing functionalized CNT (PAN(14\%)/DMF/ CNT(2\%); PSf(18\%)/NMP/CNT(2\%); PES(21)/PVP/DMAC/CNT(1\%)); data from ref. 56, 69 and 90 .

nonpolar-hydrophobic to polar-hydrophilic CNT so that the polar-polar interaction between hydrophilic CNT and organic solvents is well developed. Moreover, it also will enhance the interaction bonding between CNT and polymer in a CNT/ polymer mixed solution that results in a higher dispersion CNT in the polymer matrix. Later, a higher dispersion of CNT in organic solvents as well as in a polymer matrix will produce a membrane with a higher compatibility structure. Thus, it will further improve membrane performance. Further information about dispersion of CNT in solvents (both aqueous and nonaqueous) and approaches to improve the dispersion ability of CNT can be found in the literature. ${ }^{\mathbf{1 3 1}}$

\section{Physical characteristics: pore size, porosity and membrane morphology}

The rheological properties of membranes are changed after the addition of CNT in a membrane. The change in rheological

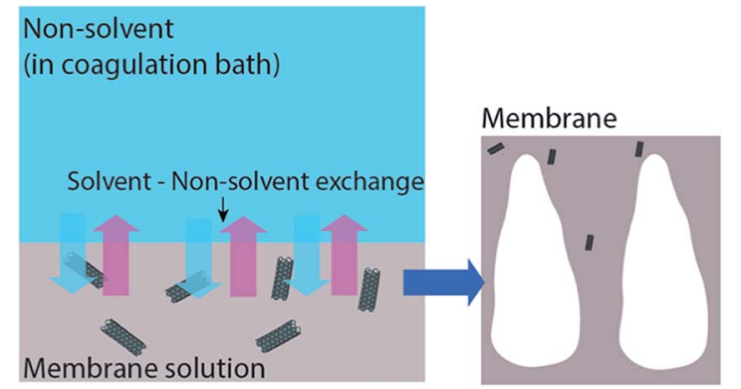

Fig. 5 Illustration of functionalized CNT (in membrane solution) effect on membrane formation during the phase inversion process. properties is influenced by viscosity of the CNT modified polymer solution (casting solution). The addition of CNT increased the viscosity of a pure polymer casting solution. The trend revealed that the more the CNT loading is the higher is the viscosity of the CNT/polymer casting solution. ${ }^{55,56,81,85,90}$ The increase in viscosity is due to the occurrence of a strong network and interaction of the CNT-polymer matrix. ${ }^{56,90}$ This strong network determines the exchange process between solvent and non-solvent (water) in the phase inversion of a membrane manufacturing process. With the existence of hydrophilic CNT in a casting solution, a strong network between CNT and polymer is increased, leading to the fast exchange event in a phase inversion process (Fig. 5). Moreover, the hydrophilicity brought by functionalized CNT enhances water entering the casting solution, thus, exchanging the solvent position in a membrane. ${ }^{63}$ This exchanging phenomenon has increasingly resulted in empty spaces in membrane structures. These empty spaces were called nodular structures ${ }^{\mathbf{6 3 , 6 4 , 8 0 , 8 3 , 8 4}}$ or macrovoids structures. ${ }^{73,74,90}$ Moreover, some mentioned it as a finger-like structure. $^{75-78,81,82,87,89,91}$ These empty spaces themselves are indicated as the porosity of the membranes. Therefore, by the addition of functionalized CNT, these empty spaces or porosity will be increased. ${ }^{56,63,65,69,75,77,80,84,85}$ Fig. 6 shows the morphology of polyethersulfone (PES) and modified PES membranes reported by Yang et al. ${ }^{78}$ As indicated by the figure, the modified membrane has a porous structure. In addition, a reduction of sieving coefficient was also observed which was due to a bigger pore size induced by the addition of functionalized CNT.

During phase inversion process, the migration of hydrophilic CNT throughout the solution matrix also happened and

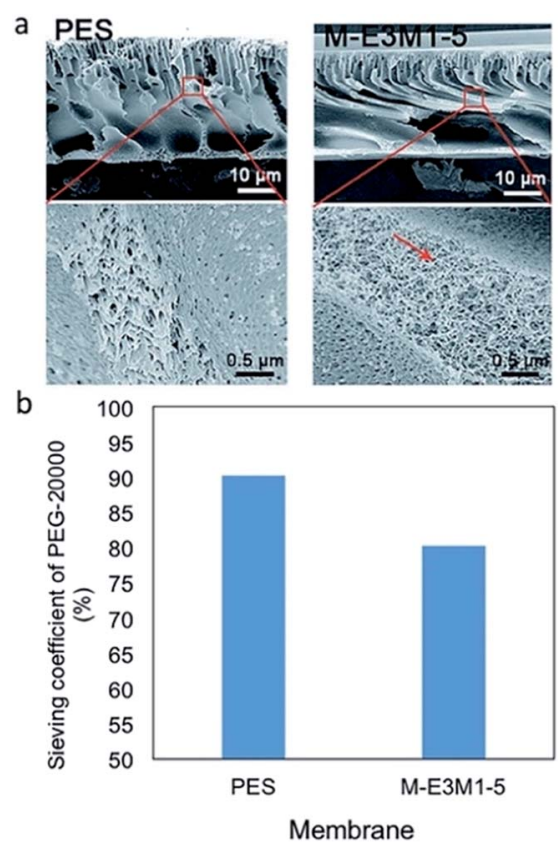

Fig. 6 Cross-section SEM images of PES and M-E3M1-5 (PES with CNT-polymethyltriethyl ammonium chloride and CNT-polyethylene glycol methyl ether methacrylate) (a) and their PEG-20000 sieving coefficient (b). ${ }^{78}$ SEM images are reproduced from ref. 78 with permission from The Royal Society of Chemistry. 

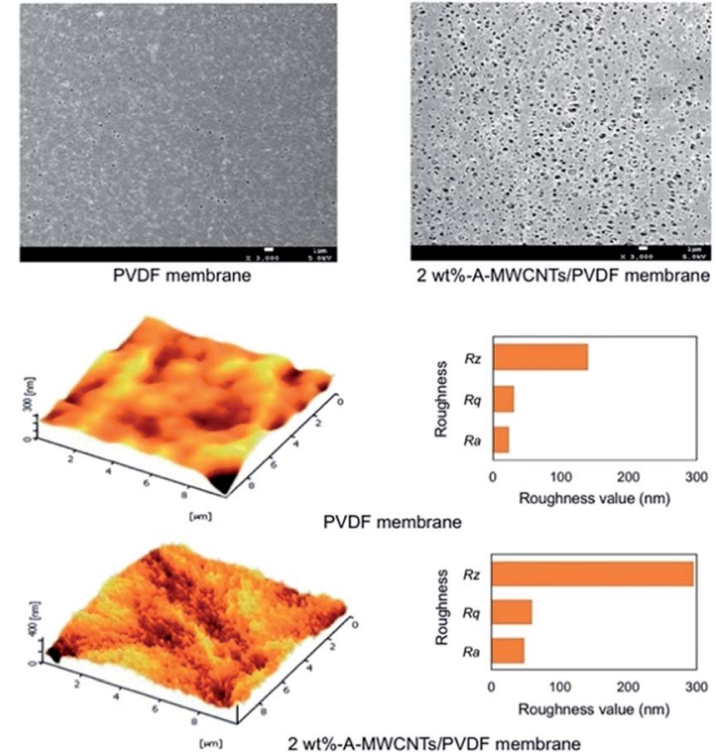

Fig. 7 FESEM images of the top surface (a) and AFM topographies of PVDF and A-MWCNT/PVDF membranes (A-MWCNT: 3-aminopropyltriethoxysilane-MWCNT) (b). Reproduced from ref. 132 with permission from The Royal Society of Chemistry.

ended in a collocated formation on the membrane's surface. ${ }^{55,56,63,65,73,91}$ The migration behavior of CNT to the surface of a membrane is also aimed to reduce the interface energy ${ }^{65,69,73}$ In a visual picture, the top surface of a prepared membrane is darker compared to the bottom side. A part of CNT collocation is proved by a higher pore size on the membrane's surface..$^{55,69,75,77,80,84,85,132}$ At the same time, a rougher membrane surface is created. ${ }^{69,73,75,81,85,91,132}$ The changes of membrane surface pores and roughness due to the addition of functional CNT are shown in Fig. 7. However, in some cases, an addition of CNT generates a smoother surface than the base membrane. ${ }^{46,74,83}$ This might be due to the fact that a CNT dose is not adequate enough to change membrane morphology.

The addition of functionalized CNT has increased the exchange process in phase inversion which lead to form remarkable modified membranes with a higher pore size, bigger porosity, and rougher membrane surface (Fig. 7). Moreover, the trend is the more CNT loading is the more changes in rheological properties there are. Nevertheless, the formation of membrane rheological properties is limited by the rheological percolation threshold. The rheological percolation threshold indicates the maximum CNT loading in a polymer matrix before the condition that a CNT-CNT interaction is preferred rather than a CNT-polymer interaction. ${ }^{55}$ The excessive CNT loading in a polymer matrix, which causes high viscosity, will be jamming kinetic diffusion followed by rheological hindrance or delayed exchange between solvent and non-solvent in a phase inversion process. ${ }^{55,90}$ Thus, it will result in irregular collocation of CNT in a membrane. ${ }^{63,90}$ Moreover, excessive CNT loading in a polymer will affect its high density structure and strong compactness ${ }^{\mathbf{4 6 , 6 5}}$ which possibly decreases either pore size or porosity of the membrane..$^{39,69,74,90}$ In the same way, it will cause smooth surface characteristics on membrane surfaces. ${ }^{64,91}$ Therefore, controlling optimum CNT loading in a polymer is important to achieve optimum rheological properties of the membrane. The details of change in number of membrane properties obtained by the optimum dose ratio of each of the groups can be seen in Table 3. Later on, a CNT modified membrane with remarkable properties will improve membrane performances.

\section{Chemical characteristic: hydrophilicity and hydrophobicity of membrane}

The addition of CNT is also found to give a chemical characteristic to a membrane. This chemical characteristic is recognized as hydrophilicity. Water contact angle has been commonly used as the indicator for describing hydrophilicity. The improvement of membrane hydrophilicity is indicated by comparing the water contact angle of a modified membrane with the base membrane. The decrease in contact angle describes the increase in hydrophilicity of a membrane. Inspired by the sessile drop method, ${ }^{\mathbf{1 3 3}}$ a hydrophilic membrane fastens liquid drop transport through a membrane leading to the decrease of formed water angle.

It can be seen in Table 3 that the addition of hydrophilic CNT in a polymer has mostly resulted in the decrease of contact angle CNT. The decreased water contact angle is provided by the hydrophilic groups given by functionalized CNT. ${ }^{55,56,63-65,69,73-78,80-89,91,134}$ Moreover, the trend shows that the more the CNT loading is the more is the decrease of contact angle due to the greater hydrophilic property given..$^{55,56,63-65,69,73-77,80,82,85,86,88,89,91,134}$ Similar with a physical characteristic, the contact angle is decreased again when an excessive dose of CNT is loaded. It may be implied that excessive CNT loading is preferred to form a dense membrane surface structure rather than to generate hydrophilicity. ${ }^{55,56,63-65,69,73-77,80,82,85,86,88,89,91,134}$ In a practical test, the denser and lower pore size will highly retain liquid drops on a membrane's surface so that the formed water contact angle increases. Therefore, the contact angle degree of the modified membrane is decreased by larger surface pore size as well as porosity of the membranes leading to the fastened water passing throughout the membrane. Conclusively speaking, controlling the optimum CNT loading in polymer is important to achieve optimum hydrophilicity for a modified membrane. This hydrophilicity is aimed to overcome the fouling problem in membrane operations. The optimum dose ratio obtained by each of the groups are shown in Table 3.

Functionalized CNT is also used for preparing membranes which need high hydrophobicity, such as membrane distillation. High hydrophobicity indicated by a high water contact angle is needed for membrane distillation to maintain flux stability. Wetting in microporous membranes used in membrane distillation can increase mass transfer resistance and thus reduce the flux of water vapor during the process. Several studies on preparing functionalized CNT membranes for membrane distillation have been reported. Dumée et al. prepared a composite CNT membrane for membrane distillation using a functionalized CNT membrane. ${ }^{135}$ Functionalization was aimed to improve mechanical stability and to maintain 
a high hydrophobicity with the CNT membrane. The CNT was functionalized via UV/ozone treatment combined with chemical reaction. The first treatment was used to create hydroxyl groups while the latter used to attach alkoxysilane-based groups. They found that the functionalized CNT membrane showed a relatively higher water contact angle $\left(140^{\circ}\right)$ and flux rather than the nascent CNT membrane produced in their previous study. ${ }^{60}$ The increased hydrophobicity was due to the presence of functional groups attached after silanation of CNT. Roy et al. prepared a functionalized CNT/polypropylene membrane for membrane distillation. ${ }^{\mathbf{1 3 6}}$ The prepared membrane showed a good distribution of functional CNT particles in the membrane matrix. This was reported as the result of functionalization and also the addition of hydrophobic polymer (mixed with CNT polyvinylidene difluoride) during membrane preparation. The water vapor flux in functionalized the CNT membrane was suggested as the effect of several mechanisms, namely: interaction of water vapor with carboxylic functional groups, adsorption of water vapor by CNT, direct diffusion through membrane pores, and interaction of water vapor with the membrane matrix which has a higher hydrophobicity due to addition of a hydrophobic polymer. The increased flux of the functionalized CNT membrane was associated with the first mechanism. The enhanced flux in membrane distillation with a carboxylatedCNT membrane was also observed by Bhadra et al. ${ }^{137}$ MoralesTorres et al. ${ }^{138}$ modified CNT (single and multi-wall) via nitric and sulfuric acid hydrothermal oxidation. The oxygenated CNT contributed to the higher affinity of affinity of water vapor to the membrane which enhanced the membrane flux. The oxygenated CNT also improved salt rejection due to electrostatic repulsion of anions with the negative charge of CNT. The increase of functionalized CNT membrane hydrophobicity used for membrane distillation also was reported by Bhadra et al. That membrane was modified with two layers created by different functionalized CNT. For the hydrophobic layer, CNT functionalized with an octadecyl amine group was used. Meanwhile, the hydrophilic side was modified by carboxylated CNT. It was expected that the hydrophobic layer improved water vapor permeation due to the increased water contact angle from $110^{\circ}$ to $125^{\circ}$. In addition, the hydrophilic layer on the permeate side was aimed to facilitate water vapor condensation. Improvement of functionalized CNT membrane hydrophobicity for membrane distillation was also achieved by An et al. ${ }^{\mathbf{1 3 9}}$ in their study. Functionalized CNT was synthesized via fluorosalinization using $1 \mathrm{H}, 1 \mathrm{H}, 2 \mathrm{H}, 2 \mathrm{H}$-perfluorooctyltriethoxysilane (FTES). The fluorinated CNT successfully improved the dispersion of CNT in the membrane matrix as well as hydrophobicity of the membrane. The functional group improved interaction of CNT particles with the membrane polymer which resulted in a good dispersion. The addition of functionalized CNT created a superhydrophobic membrane with a contact angle of about $150^{\circ}$. The functionalized CNT membrane exhibited an increased surface roughness that increased water contact angles and hydrophobicity.

Table 3 Modified membranes properties given by the optimum ratios of functionalized CNT in membrane matrix

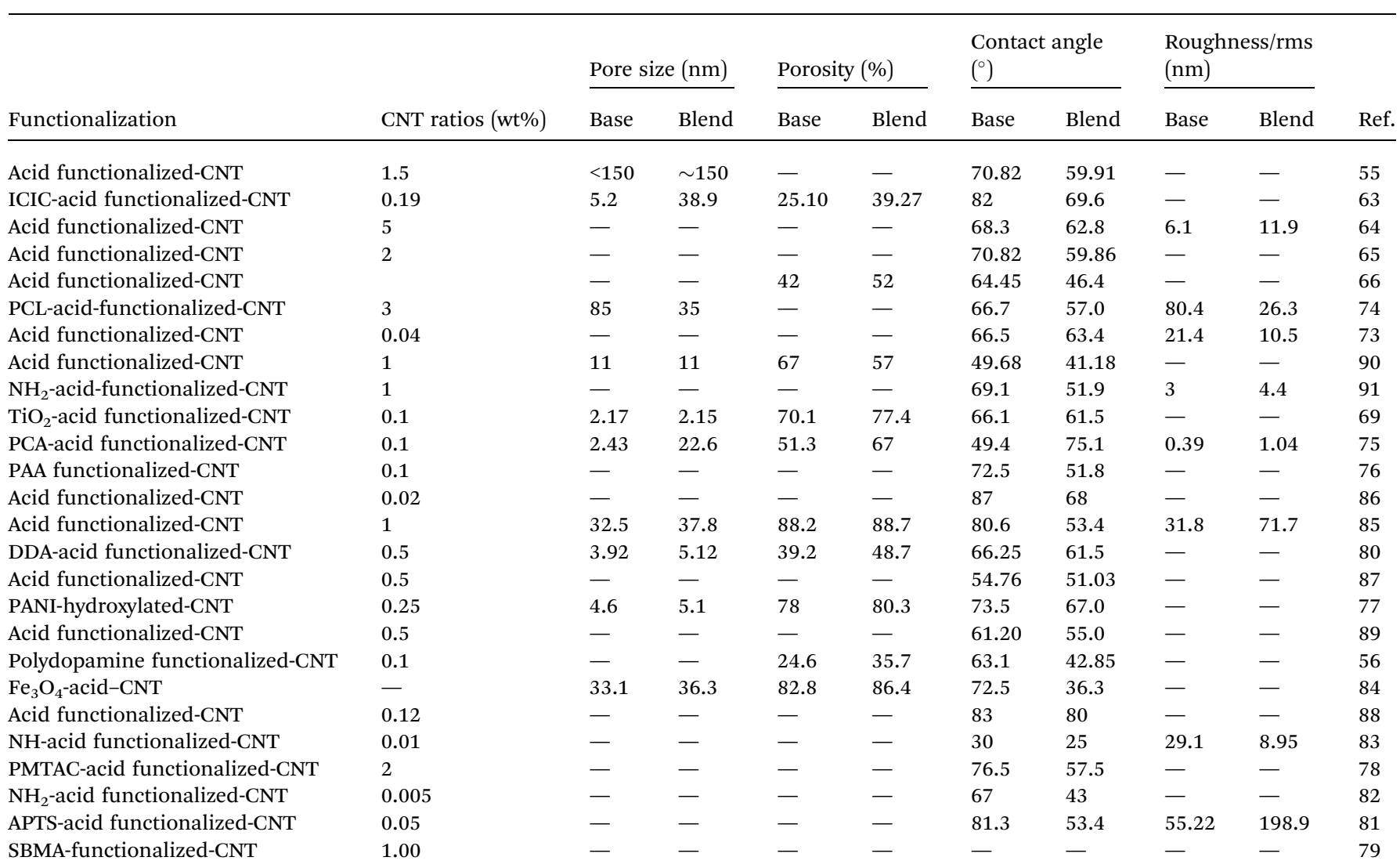




\section{Performance of functionalized CNT membrane}

\section{Permeability and rejection performances}

In the beginning, CNT functionalization was aimed to make CNT hydrophilic so that they will be well distributed in a polymer matrix. Fortunately, hydrophilicity also plays an important role to enhance membrane performances. Results showed the presence of functionalized CNT improved the performances of modified membranes. Most groups obtained a higher permeability for modified membranes than the base membrane. The improvement is due to the role of hydrophilic CNT in increasing the hydrophilicity of a modified membrane. ${ }^{55,56,63-66,69,73-78,80,82-91}$ The hydrophilicity is generated by hydrophilic groups attached to a functionalized CNT wall, as proven by the decrease of contact angle of a modified membrane (see Table 3). The improvement of membrane permeability also might be due to a bigger pore size as well as porosity of the modified membrane made by the presence of CNT in the membrane matrix. ${ }^{55,63,75,80,84,85}$ In the case of mixed-matrix CNT membranes prepared by phase-inversion and solution precipitation methods, the formation of high porosity and larger pore size may be due to interaction of CNT in the casting solution with non-solvent in a phase inversion process. The hydrophilic and adsorption characteristics of functionalized CNT could lead to fast exchange of solvent and non-solvent during the immersion which results in a membrane with high porosity ${ }^{5,63,64}$ (Fig. 5-7). As the result, a UF membrane with high water permeability is produced. In the case of NF and RO membranes, the addition of a functionalized CNT layer as an intermediate layer of the support could improve permeability of the membrane due to the increase of support hydrophilicity and porosity. ${ }^{87}$ The adsorption and hydrophilic characteristics, and also porous

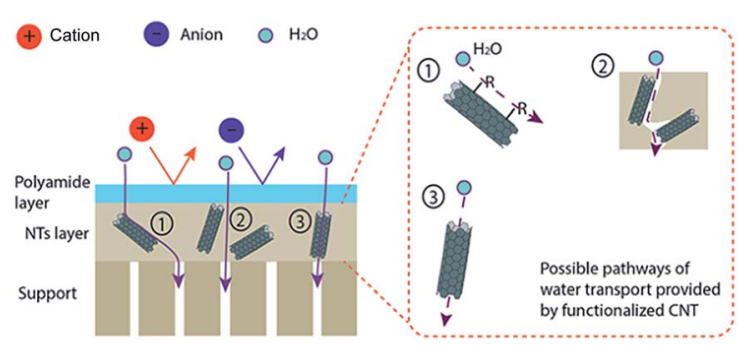

(a)

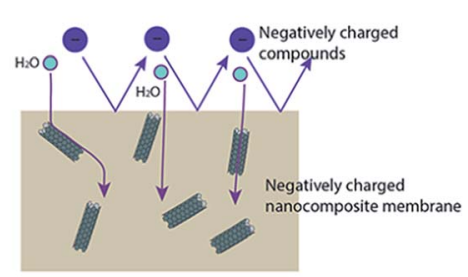

(b)

Fig. 8 Mechanism of functionalized CNT (mixed-matrix) in improving membrane performance. (a) Possible pathways of water transport provided by functionalized CNT and (b) rejection of negatively charged compounds. structure of the functionalized CNT, could provide more pathways for water transport that enhance overall water permeability of the membrane (Fig. 8).

Furthermore, the addition of functionalized CNT in a polymer matrix has also formed a modified membrane with remarkable rejection performance (see Table 4 ). It showed that the hydrophilicity brought by the functionalized CNT increased the rejection performance of modified membranes. ${ }^{56,65,66,69,73-78,80,82-84,87,89,91}$ The two well-known rejection mechanisms in membrane filtration have been supported by the existence of hydrophilic CNT, including electrostatic repulsion and Donnan exclusion. Electrostatic repulsion occurs between a membrane surface and organic substances while Donnan exclusion happens between a modified membrane and inorganic substances. As it is called electrostatic repulsion, membrane surfaces and substances are conditioned to have the same charge in order to get an optimum repulsion performance. In this case, organic substances are found to be negatively charged in the filtration operation condition (neutral $\mathrm{pH}$ ). Some reports related the behavior of organic substances' surface charge to isoelectric point (IEP). The IEP is in the range of $\mathrm{pH} 4-5$. The organic substance has a negative charge when the $\mathrm{pH}$ value is above the IEP. Meanwhile, hydrophilicity of modified membrane is defined as negatively charged properties. By these conditions, the repulsion between an organic substance and the membrane surface occurred (Fig. 9).

Similar to electrostatic repulsion, Donnan exclusion is utilized through a negatively charged surface of a modified membrane and the same negative charged ions (co-ions) of an inorganic substance. An optimum Donnan exclusion occurred after electrochemical equilibrium between solution and membrane. When a negatively charged membrane contacts with an electrolyte solution, the concentration of co-ions which have the same charge with the membrane will be repulsed on the membrane's surface. Moreover, the counter ions which have a different charge with the membrane will be attracted to the membrane's surface. As a result, the co-ions concentration in solution will be higher than on the membrane's surface. Meanwhile, the counter-ions presence in solution will be lower than on the membrane's surface. These conditions make a potential difference at the interface phase between the solution phase and the membrane surface phase which leads to generate an electrochemical equilibrium between those phases. Once electrochemical equilibrium is reached, co-ions are repelled by the membrane whereas the counter ions are attracted (Donnan exclusion). ${ }^{73}$ This mechanism is consistently well explained by Nilsson et al. and Peeters et al. ${ }^{\mathbf{1 4 0 , 1 4 1}}$ Furthermore, that ions repulsion process is also depended on ionic strength and valence of the ions. ${ }^{73,141} \mathrm{~A}$ set of bivalent negatively charged ions (co-ion) with bivalent positively charged ions (counter-ion) will be highly repelled. On the other hand, lower exclusion will be obtained by a set of monovalent co-ions and monovalent counter-ions. ${ }^{73,141}$

Most all groups have produced a modified membrane with higher rejection than the base membrane. ${ }^{56,65,66,69,74-78,80,82-84,89,91}$ This is due to the hydrophilicity characteristic of a modified membrane as explained previously. The improved 


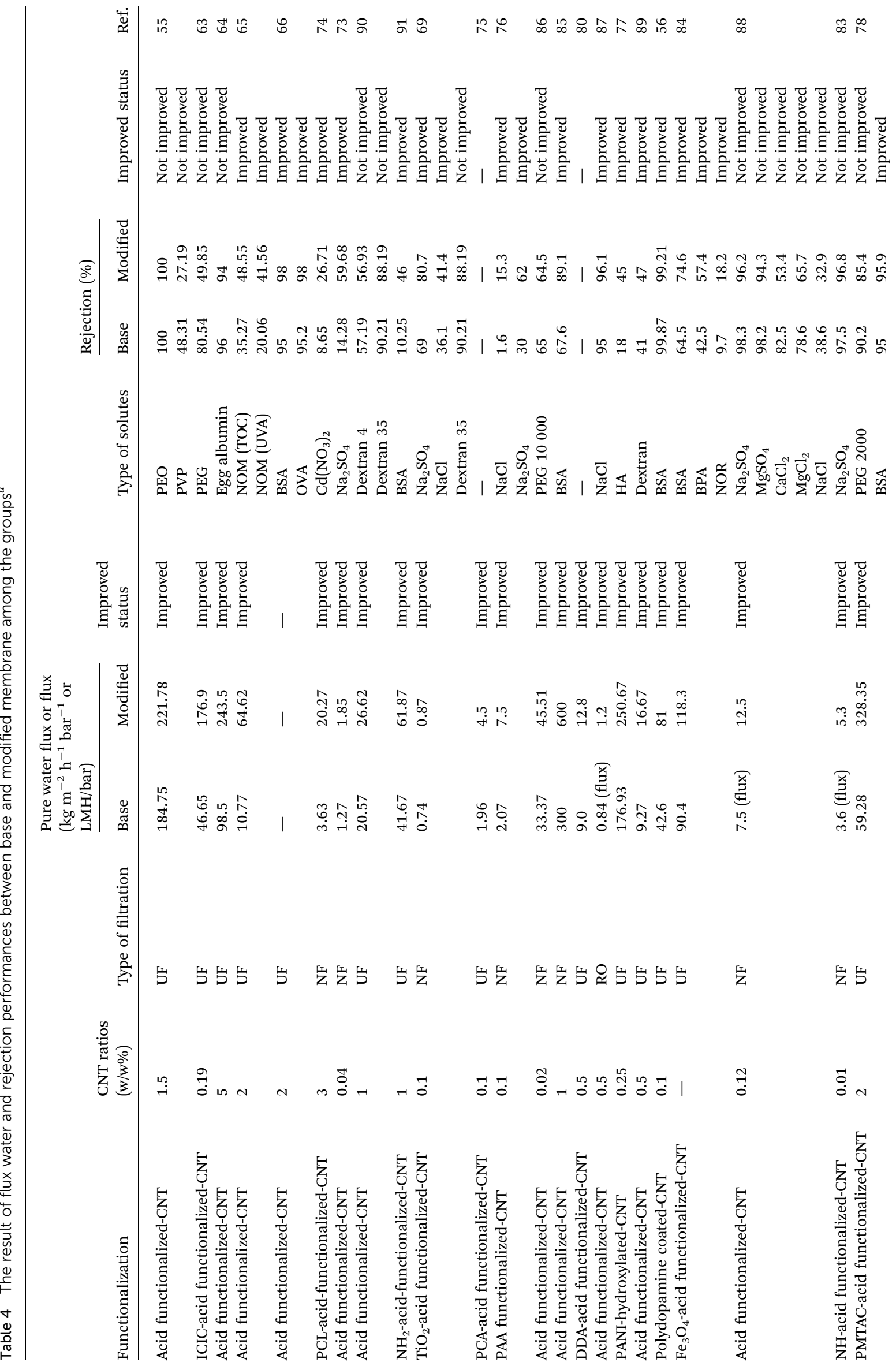


hydrophilicity is proved by the decrease of contact angle (see Table 3). Nevertheless, Choi et al. and Qiu et al. showed lower performance for rejection compared with the base membrane. ${ }^{55,63}$ Meanwhile, Wu et al., Majeed et al., Phao et al., Wu et al., and Xue et al. revealed a slightly lower rejection performance than the pure membrane. ${ }^{64,83,86,88,90}$ The unimproved rejections are due to incompatibility of the membrane structure even after the addition of functionalized CNT. A delayed exchange process between solvent and non-solvent in the phase inversion process has resulted in the irregular collocation of CNT in the membrane. ${ }^{55,63,86,90}$ Looking at those two organic/inorganic substance rejection performances, the improvement of rejection performance of a modified membrane lies on the negatively charged surface property which is mainly contributed by the hydrophilic groups carried by functionalized CNT. However, the molecular weight (MW) or ion radius size (valent number) of organic or inorganic substances can also influence the rejection performance. The higher the MW or valence number of a substance, the higher rejection will be obtained, and vice versa..$^{55,56,66,69,73,82,84,88}$

\section{Anti-trade-off between permeability and rejection performances}

The most intensive discussion in membrane fields is the tradeoff problem between permeability and rejection, especially in the case of desalination. Making a membrane hydrophilic by the introduction of CNT into a membrane matrix is effective to achieve the desired property. Based on review results, it was seen that some groups have successfully manufacture modified membranes with anti-trade-off between permeability and rejection properties. ${ }^{39,56,65,69,73,74,76-78,82,84,85,87,89}$ Some of the results are depicted in Fig. 9. Membranes with functionalized CNT showed higher flux and rejection compared to their base membranes. Even at a considerably high increase of the flux, some of the membranes containing functionalized CNT exhibited a slight reduction in salt rejection.

The mechanism of anti-trade-off between permeability and rejection is illustrated in Fig. 8b. When organic/inorganic solution contacts with negatively charged membrane, the organic substances which have the same charge with membrane will be repulsed on membrane surface. At the same time, the hydrophilic-modified-membrane will strongly attract water which well known as hydrophilic substance. Absorption ability of CNT and hydrophilic nature of functionalized CNT can increase water permeability of the modified membrane. As the water permeability increases at the same operating condition, the amount of water transported through the membrane is higher than the salt. Therefore, both water permeability and salt rejection of the membrane are improved. Unfortunately, the trade-off problem still occurred in some studies. ${ }^{55,63,64,81,83,86,88,90}$ In the case of lower rejection, it seems the incorporation of CNT in the modified membrane matrix was hindered by a poor interfacial compatibility of the CNT with the polymer, leading to unselective voids. Moreover, the trade-off problem also occurring due to the influence of larger pore size is preferred over the repulsion affected by hydrophilic CNT throughout the polymer matrix..$^{55,64,90}$ 
(a)

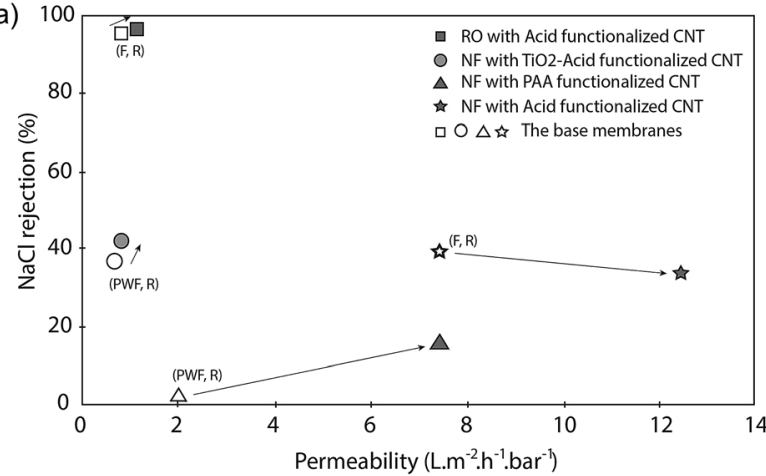

(b)

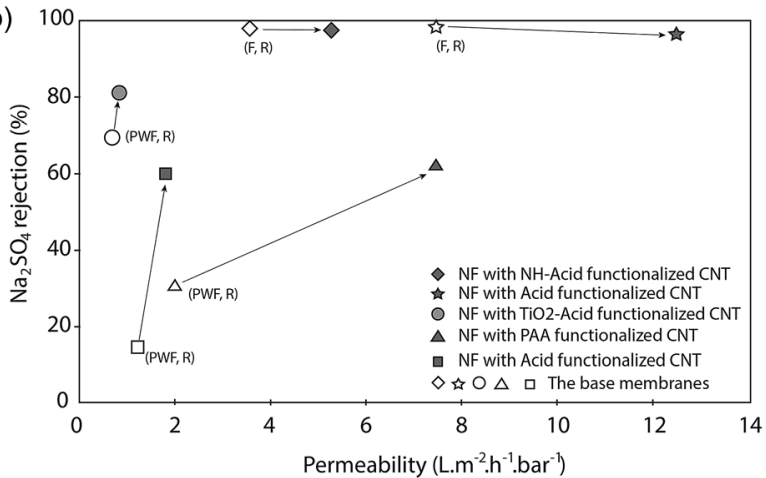

Fig. 9 Permeability vs. rejection of a functionalized CNT membrane. (a) $\mathrm{NaCl}$ rejection and (b) $\mathrm{Na}_{2} \mathrm{SO}_{4}$ rejection (data from ref. 69, 73, 76 , 83, 87 and 88; F: permeability of salt solution; PWF: permeability of pure water; R: salt rejection)

Meanwhile, Zeng et al. faced a trade-off problem due to lower permeability. ${ }^{81}$ It might be due to blockage of the pore surface by CNT which results in decreasing water flow through the membrane. Considering those problems, it could be implied that the functionalization method of CNT strongly influences the role of functionalized CNT in improving membrane properties and performances. Some functionalization types introduced by groups are effective and some others still face the same problems. Regardless of the risk of an ineffective functionalization method, the idea of making CNT hydrophilic in membrane applications is still attractive to develop due to its remarkable properties as a filler in polymer matrix.

\section{Anti-fouling performances}

One of the purposes making a membrane hydrophilic by adding functionalized CNT is to improve its antifouling property. Interestingly, all the groups which were investigated for antifouling performance achieved improvements in their modified membranes (see Table 5). Flux recovery ratio (FRR) and total fouling resistance $\left(R_{\mathrm{t}}\right)$ parameters are used to quantify membranes antifouling performances. FRR defines recovery ability of the membrane from a fouling event while $R_{\mathrm{t}}$ defines total fouling number occurring on the membrane surface. Improvement of antifouling performance is closely related to the role of hydrophilicity with modified membranes in a rejection mechanism as explained in a previous section. The tendency of organic substances attached and trapped on a membrane's surface is reduced due to the repulsive interaction between negatively-charged-hydrophilic membranes and negatively charged substances (Fig. 8b). With these conditions, the modified or functionalized CNT membrane exhibits higher flux stability than the base membrane. On the other hand, the permeability of a fouled membrane is presumed to be still high due to the hydrophilicity of the membrane strongly attracting more water to pass through it. So, the permeability of a fouled membrane still can be highly recovered. The high permeability of a fouled membrane during operation and after backwash decreases $R_{\mathrm{t}}$ and increases the FRR number, respectively. Improvement of the antifouling property of functionalized-CNT membranes is indicated by a higher FRR as well as a lower $R_{\mathrm{t}}$ compared to the base membrane. ${ }^{56,65,69,73,75,79,80,87,89,91}$

In detail, a characteristic of modified membrane is that it shows higher reversible fouling resistance $\left(R_{\mathrm{r}}\right)$ and lower irreversible fouling resistance $\left(R_{\mathrm{ir}}\right)$ while the base membrane characteristic reveals higher $R_{\mathrm{ir}}$ and lower $R_{\mathrm{r}}$. Higher $R_{\mathrm{r}} / R_{\mathrm{ir}}$ means reversible/irreversible fouling is dominated on a membrane, respectively. Either $R_{\mathrm{r}}$ or $R_{\mathrm{ir}}$ explains more about

Table 5 Membrane performances for fouling parameters among the groups

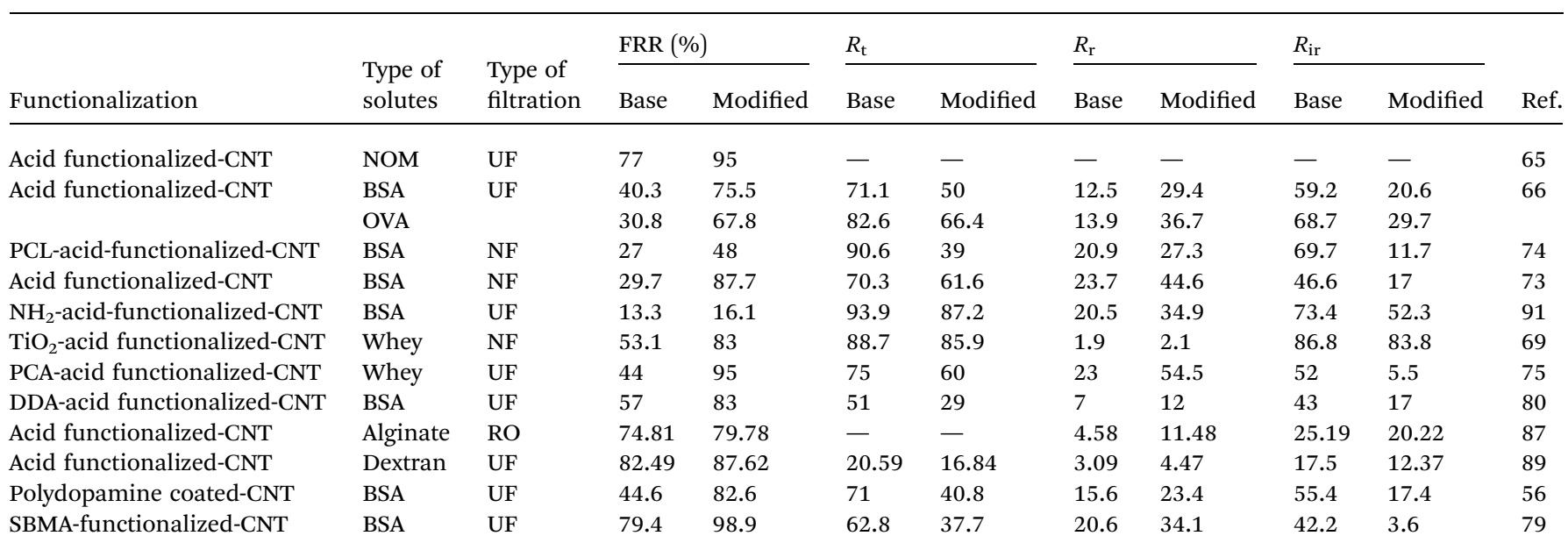




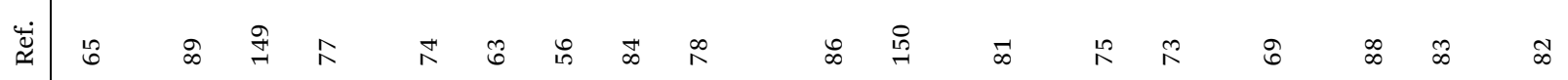

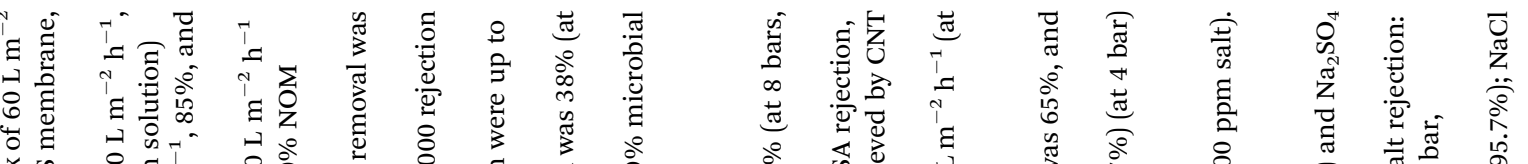

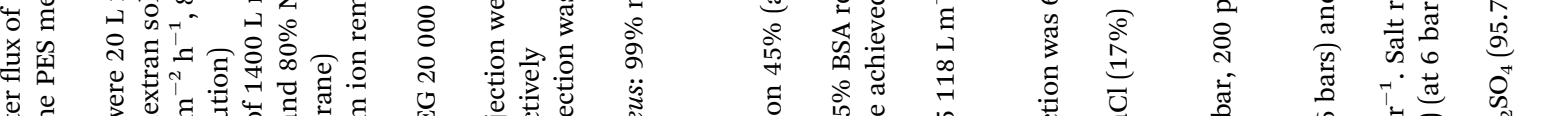

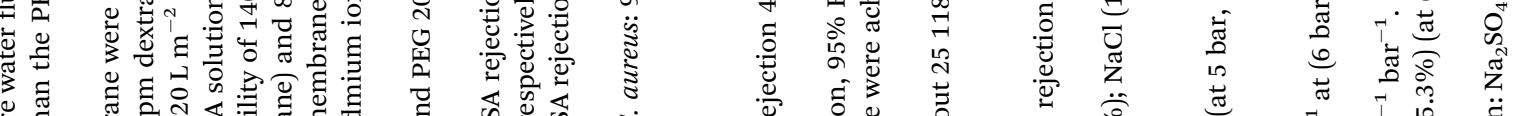

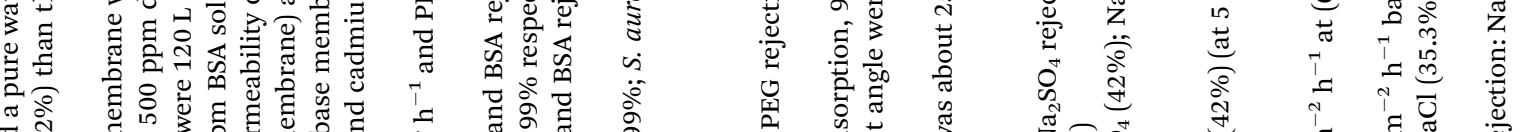

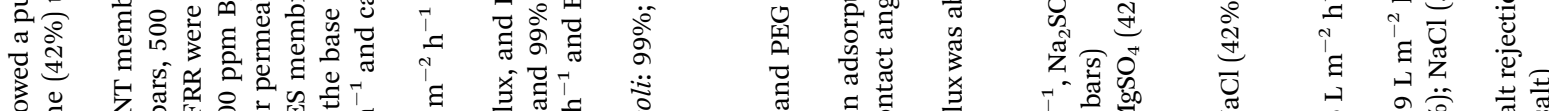

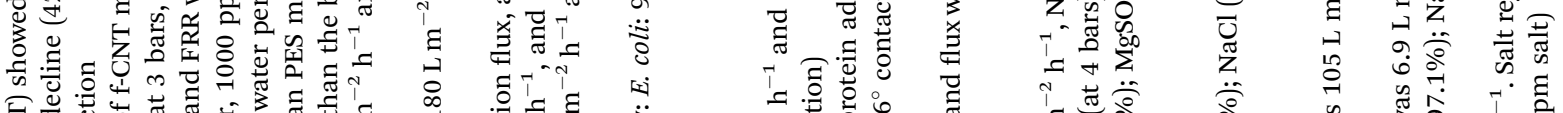

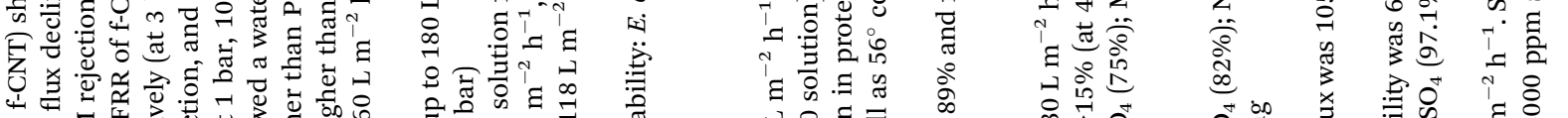

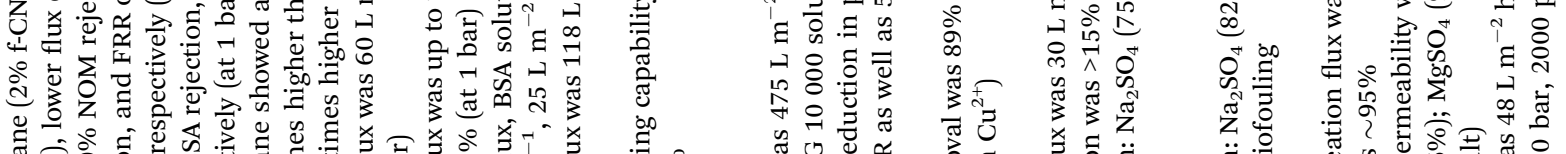

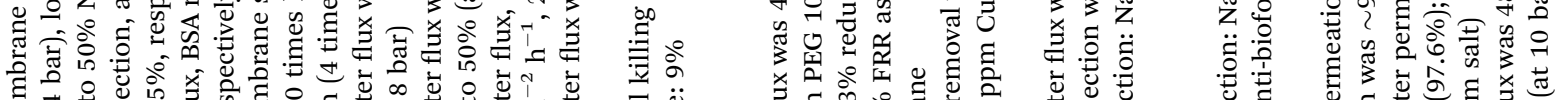

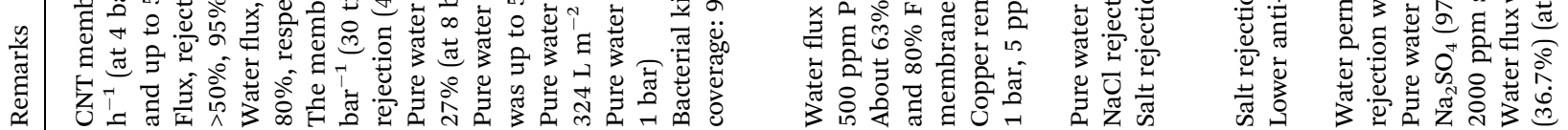

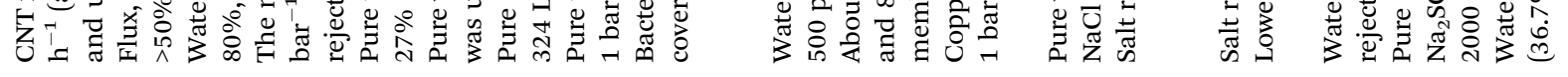

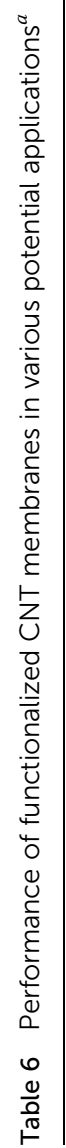

Winn

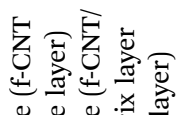

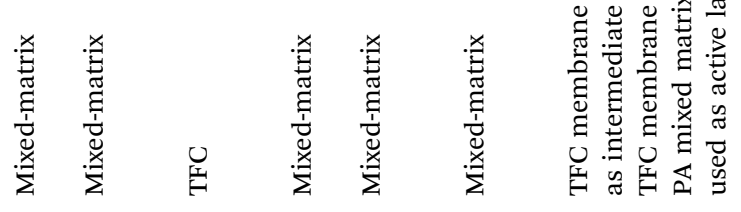

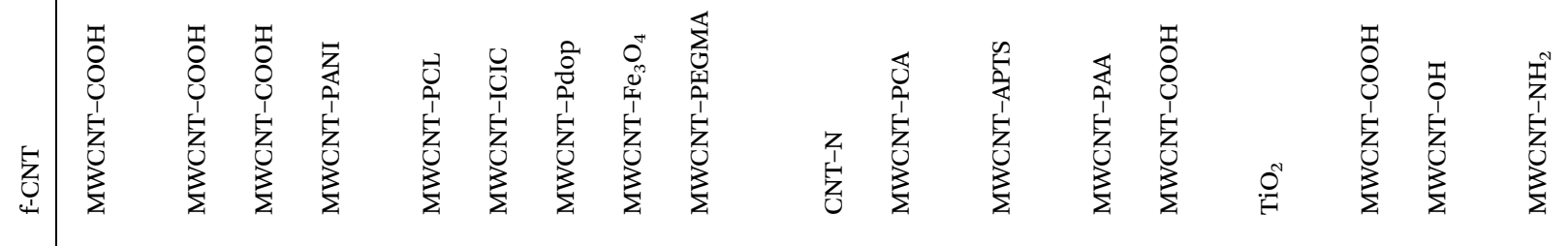

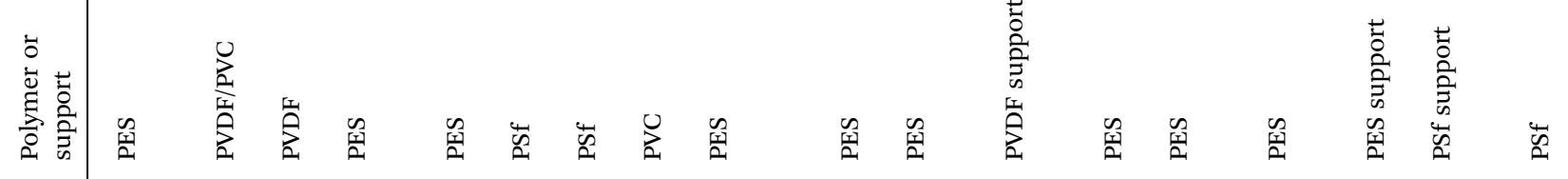




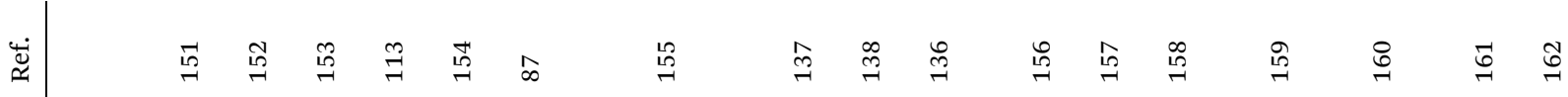

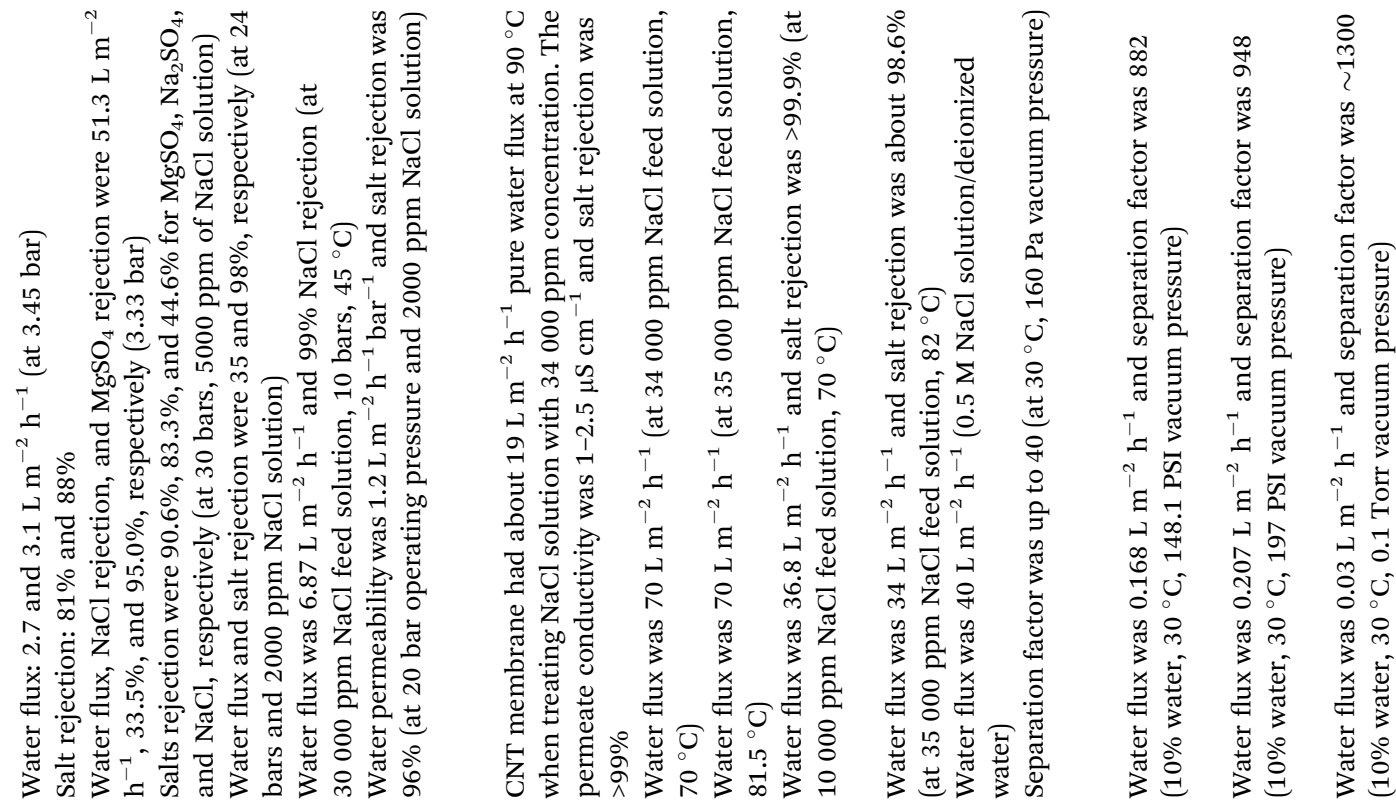

希崖

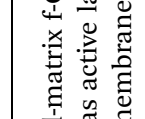

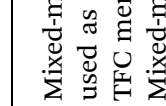

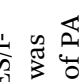

烈

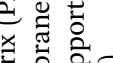

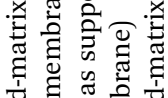

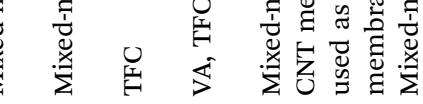

辰高

II

\section{$\underbrace{+1}_{x}$}

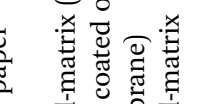

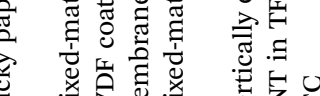

焉

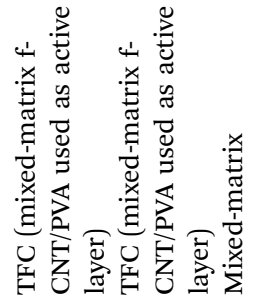

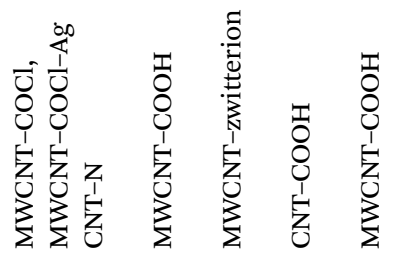

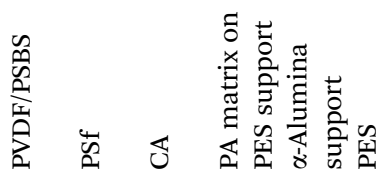

官

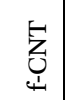

क

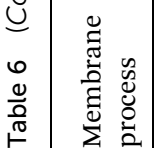

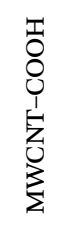

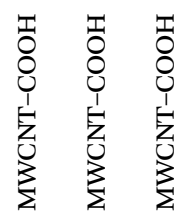

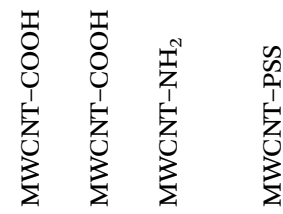

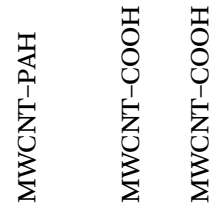

(2)

灰. 


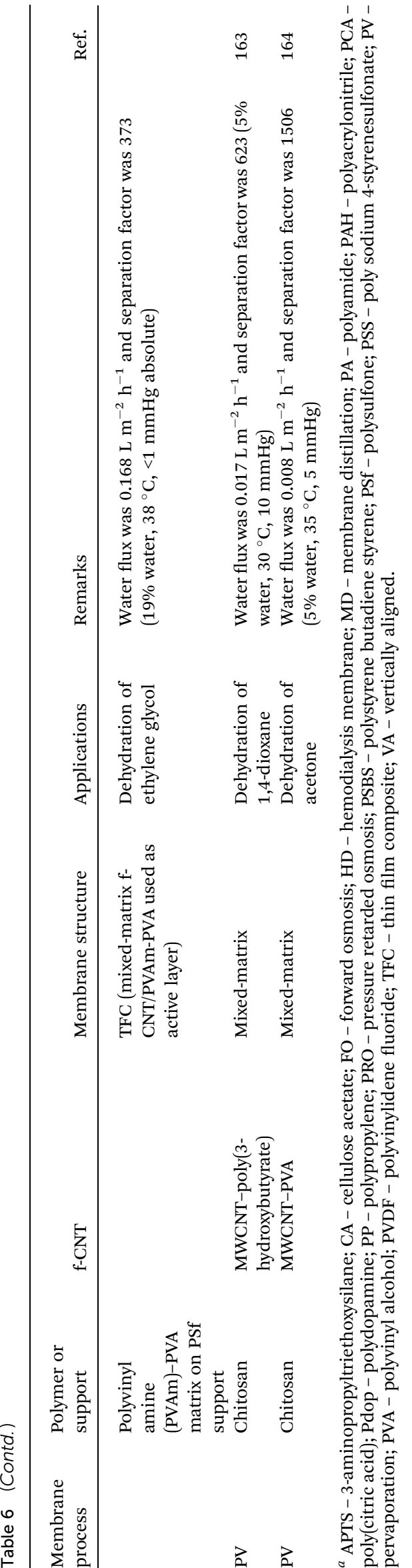

the fouling types that happened between a modified and unmodified membrane. Reversible fouling indicates easiness of foulant removal from the membrane. Meanwhile, irreversible fouling indicates the difficulties in foulant removal from a membrane due to strong adsorption of a substance on the membrane surface or entrapment of substances in the membrane pores. The easiness in cleaning of a fouled membrane is related to the stability of foulant substance on its surface. It is well known that hydrophobicity of the base membrane tends to trap a foulant substance on the membrane's surface, leading to difficulties in cleaning the foulant..$^{3,34}$ Meanwhile, hydrophilicity of the modified membrane is preferred to repulse foulant to attach, thus promoting the unstable attachment of a substance on the membrane's surface and making it easy to clean. ${ }^{56,65,73,79,89,91}$ Therefore, the improvement of antifouling in a modified membrane is determined as the higher $R_{\mathrm{r}}$ and lower $R_{\mathrm{ir}}$ number (see Table 5). Besides improving membrane hydrophilicity, controlling the $\mathrm{pH}$ of the feed solution is important to obtain an effective repulsion. By setting $\mathrm{pH}$ of the solution higher than the IEP of an organic substance, it generates a negatively charged substance leading to a repulsion interaction between organic substances and the membrane surface. ${ }^{65}$ When the $\mathrm{pH}$ of a solution is less than the IEP, the substance will be denatured $^{73,142}$ making a thin dense layer on the membrane surface. This thin dense layer formed on the membrane surface will decrease its permeability. ${ }^{73,143,144}$ Therefore, to achieve a remarkable antifouling performance, the focus is not only put on CNT functionalization but also adjustment of $\mathrm{pH}$ in a solution so that the advantage of repulsive interactions between the negatively charged substance and the negatively charge on the modified membrane surface can be obtained. ${ }^{56,65,75}$

Results of some studies also showed the important role of membrane rheological properties, including surface roughness, in improving the antifouling property. A membrane with lower roughness (smooth surface) has stronger antifouling abilities. $^{69,73,75}$ Foulants are likely to adsorb in the valleys of a membrane with the rougher surface thus resulting in these valleys clogging. ${ }^{73}$ Unfortunately, as explained before, the addition of functionalized CNT tends to make a membrane's surface rougher. However, there will be a condition that the more added CNT results in a smoother surface. ${ }^{73,91}$ Therefore, by carefully controlling CNT dose ratio in a polymer matrix, a membrane with appropriate surface roughness can be synthesized.

\section{Recent applications of CNT membranes}

The potential application of CNT membranes is associated with the unique properties of CNT regarding water molecules transport. The "ultra-efficient transport of water molecules" ${ }^{\mathbf{1 4 5}-\mathbf{1 4 7}}$ in a CNT membrane is beneficial for membranes such as in the cases of water purification, desalination, and pervaporation. Performance of functionalized CNT membranes in various potential applications are tabulated in Table 6. High water transport through the inner tubes of CNT is attributed to the smoothness of the CNT surface. ${ }^{148}$ For functionalized CNT, 
this is also attributed to the interaction of water molecules with the functional groups or modifier attached to a CNT surface. ${ }^{\mathbf{1 2 0}}$ In mixed-matrix (non-aligned CNT) the improvement of water permeability is due to several factors which have been discussed in a previous section. Compared to a polymeric membrane used in desalination, a CNT membrane exhibited higher water permeability and salt rejection. ${ }^{62}$ Despite the excellent properties of CNT membranes, industrial applications are still under development. ${ }^{59,62}$

Performance of a functionalized CNT membrane is generally examined using synthetic solutions as previously summarized in Table 4. Treatments of real water or samples under real operating conditions are rarely reported. An example of using real feed water to examine a CNT membrane was reported by Celik et al. ${ }^{65}$ They examined the fouling of a functionalized CNT membrane with Yeongsan River water. ${ }^{65}$ A long-term permeation test (for $8 \mathrm{~h}$ at operating pressure of $4 \mathrm{bar}$ ) showed a lower fouling tendency $(42 \%$ less $)$ than with the unmodified membrane. This study indicates the applicability of a functional CNT (acid treated CNT) in improving the anti-organic fouling property of an ultrafiltration membrane under a real-world condition. Desalination as the major study of functionalized CNT membranes (NF, RO, MD) was only performed using synthetic solutions. Nevertheless, some of them tried to operate under high operating pressure close to a real operating pressures. The study indicated that the membrane could withstand such conditions. A real solution treatment may show a different behavior of membranes due to the presence of impurities. Therefore, for future work, performance tests of functionalized CNT membranes using real solutions and real operating conditions should be considered.

\section{Conclusion and future outlook}

CNT functionalizations performed by all studies are successful in generating hydrophilic groups on CNT. The existence of hydrophilic groups on a CNT surface has resulted in good dispersion of CNT in solvents as well as in a polymer matrix. These have led to excellence membrane properties including lower contact angle (increased hydrophilicity), bigger pore size, higher porosity, and rougher/smoother structure which was followed by remarkable membrane performances such as increased permeability, increased rejection, anti-trade-off between permeability and selectivity, and antifouling properties.

During these last 10 years, approaches of CNT functionalization were focused on: (1) acid treatment (oxidation); (2) acid treatment followed by other approaches such as in situ polymerization and hydrophilic groups or inorganic material attachment; (3) direct functionalization through in situ polymerization on CNT walls. In addition, some studies also introduced a linkage agent (additive) into the polymer to enhance interactions between CNT and the polymer. Interestingly, acid treatment was applied by almost all studies due to some advantages including opened tips and shortened length CNT which will facilitate the conversion of terminal carbon to carboxylic groups and increase CNT dispersion throughout the polymer matrix. However, the weakness behind this treatment is wall breakage in CNT and decreased structural integrity of nanocomposites due to presence of carboxylic groups on the CNT surfaces. Therefore, CNT functionalization methods based on in situ polymerization or coating/attachment were used in many works. It was shown that more than half of the total reports after the year 2011 are directed to these functionalization methods.

It seems the functionalization of CNT, especially for membrane preparation, will be more established based on polymerization and coating/attachment concept in the future. Some long-chain functional groups that have potential to make CNT hydrophilic are PAH, poly(diallyl dimethyl ammonium chloride) (PDADMAC), and poly(sodium 4-styrene sulfonate). Peng et al. and Amirilargani et al. functionalized CNT through coating CNT with PAH to make the CNT as well as poly(vinyl alcohol) (PVA) membranes became hydrophilic. ${ }^{114,165}$ The use of $\mathrm{PAH}$ is due to their ability to make CNT stable in aqueous solution for a long time. ${ }^{\mathbf{1 1 4 , 1 6 5}}$ Iamsamai et al. coated a CNT surface with PDADMAC and PSS to make the CNT hydrophilic through polymerization, layer by layer (LbL) deposition. ${ }^{\mathbf{1 6 6}}$ The key approach of PDADMAC and PAS is to induce a sufficient electrostatic charge at a nanotube's surface in order to provide good dispersion of CNT in aqueous solution, even though they do not require tedious centrifugation-sonication steps. Furthermore, some remarkably hydrophilic moieties of polyelectrolytes that were predicted to make CNT hydrophilic are given by Hammond et al. ${ }^{167}$ and Bertrand et al. ${ }^{168}$ Polyelectrolytes, such as poly(ethylene imine) and poly(vinyl sulfate), are produced via polymerization called electrostatic layer-by-layer self-assembly (ESA) on a material's surface. ESA is recommended due to its simplicity, versatility, and speed in practicing. Therefore, these methods have potential to be applied in functionalizing CNT which can be utilized in membrane preparation. ${ }^{168}$ Modification by mimicking a biological membrane may be another interesting approach to prepare functionalized CNT membranes. Results of some studies indicated a remarkable ion rejection and high water permeability of a biomimetic CNT membrane. ${ }^{169,170}$ However, to the best of our knowledge, studies of biomimetic CNT membranes are still limited.

The progressive development and excellent performance of functionalized CNT membranes reported by many studies show that the reliability of these functionalized CNT membranes will be not only developed on a laboratory scale but also on a commercial scale. Moreover, the approaches on CNT functionalization, especially in polymerization methods, will be intensively developed in the future as more various moieties or polyelectrolytes are found. However, performance assessments of functionalized CNT membrane using real solutions and operating conditions are rarely reported, and thus should be considered for future works.

\section{Conflicts of interest}

There are no conflicts to declare. 


\section{Notes and references}

1 E. Drioli and E. Curcio, J. Chem. Technol. Biotechnol., 2007, 82, 223-227.

2 Khoiruddin, D. Ariono, Subagjo and I. G. Wenten, J. Appl. Polym. Sci., 2017, 134, 45540.

3 N. F. Himma, S. Anisah, N. Prasetya and I. G. Wenten, J. Polym. Eng., 2016, 36, 329-362.

4 I. G. Wenten, P. T. Dharmawijaya, P. T. P. Aryanti, R. R. Mukti and Khoiruddin, RSC Adv., 2017, 7, 2952029539.

5 A. G. Fane, R. Wang and M. X. Hu, Angew. Chem., Int. Ed., 2015, 54, 3368-3386.

6 B. Van der Bruggen, E. Curcio and E. Drioli, J. Environ. Manage., 2004, 73, 267-274.

7 A. K. Wardani, A. N. Hakim, Khoiruddin and I. G. Wenten, Water Sci. Technol., 2017, 75, 2891-2899.

8 I. G. Wenten, Khoiruddin, F. Arfianto and Zudiharto, Desalination, 2013, 314, 109-114.

9 D. Ariono, M. Purwasasmita and I. G. Wenten, J. Eng. Technol. Sci., 2016, 48, 367-387.

10 I. G. Wenten, H. Julian and N. T. Panjaitan, Desalination, 2012, 306, 29-34.

11 F. P. Cuperus and H. H. Nijhuis, Trends Food Sci. Technol., 1993, 4, 277-282.

12 A. W. Mohammad, C. Y. Ng, Y. P. Lim and G. H. Ng, Food Bioprocess Technol., 2012, 5, 1143-1156.

13 M. Purwasasmita, D. Kurnia, F. C. Mandias, Khoiruddin and I. G. Wenten, Food Bioprod. Process., 2015, 94, 180-186.

14 Khoiruddin, I. N. Widiasa and I. G. Wenten, J. Food Eng., 2014, 133, 40-45.

15 M. Purwasasmita, E. B. P. Nabu, Khoiruddin and I. G. Wenten, J. Eng. Technol. Sci., 2015, 47, 426-446.

16 C. A. Scholes, G. W. Stevens and S. E. Kentish, Fuel, 2012, 96, 15-28.

17 H. Strathmann, A. Grabowski and G. Eigenberger, Ind. Eng. Chem. Res., 2013, 52, 10364-10379.

18 A. S. Rathore and A. Shirke, Prep. Biochem. Biotechnol., 2011, 41, 398-421.

19 S. Lütz, N. N. Rao and C. Wandrey, Chem. Eng. Technol., 2006, 29, 1404-1415.

20 C. Charcosset, Biotechnol. Adv., 2006, 24, 482-492.

21 I. G. Wenten and I. N. Widiasa, Desalination, 2002, 149, 279-285.

22 K. Khoiruddin, A. N. Hakim and I. G. Wenten, Membr. Water Treat., 2014, 5, 87-108.

23 D. F. Stamatialis, B. J. Papenburg, M. Gironés, S. Saiful, S. N. M. Bettahalli, S. Schmitmeier and M. Wessling, J. Membr. Sci., 2008, 308, 1-34.

24 S. P. Adiga, C. Jin, L. A. Curtiss, N. A. Monteiro-Riviere and R. J. Narayan, Wiley Interdiscip. Rev.: Nanomed. Nanobiotechnol., 2009, 1, 568-581.

25 E. Bakangura, L. Wu, L. Ge, Z. Yang and T. Xu, Prog. Polym. Sci., 2016, 57, 103-152.

26 Z. Zakaria, S. K. Kamarudin and S. N. Timmiati, Appl. Energy, 2016, 163, 334-342.
27 D. Ariono, Khoiruddin, Subagjo and I. G. Wenten, Mater. Res. Express, 2017, 4, 24006.

28 I. G. Wenten and Khoiruddin, J. Eng. Sci. Technol., 2016, 11, 916-934.

29 Khoiruddin, P. T. P. Aryanti, A. N. Hakim and I. G. Wenten, AIP Conf. Proc., 2017, 1840, 90006.

30 L. Ma, X. Dong, M. Chen, L. Zhu, C. Wang, F. Yang and Y. Dong, Membranes, 2017, 7, 16.

31 X. Yang, R. Wang, A. G. Fane, C. Y. Tang and I. G. Wenten, Desalination Water Treat., 2013, 51, 3604-3627.

32 E. Drioli, A. I. Stankiewicz and F. Macedonio, J. Membr. Sci., 2011, 380, 1-8.

33 P. T. P. Aryanti, R. Yustiana, R. E. D. Purnama and I. G. Wenten, Membr. Water Treat., 2015, 6, 379-392.

34 P. T. P. Aryanti, M. Sianipar, M. Zunita and I. G. Wenten, Membr. Water Treat., 2017, 8, 463-481.

35 N. F. Himma, A. K. Wardani and I. G. Wenten, Polym.-Plast. Technol. Eng., 2017, 56, 184-194.

36 L. Dong, H. Yang, S. Liu, X. Wang and Y. F. Xie, Desalination, 2015, 365, 70-78.

37 W. Wang, E. Eftekhari, G. Zhu, X. Zhang, Z. Yan and Q. Li, Chem. Commun., 2014, 50, 13089-13092.

38 M. E. A. Ali, L. Wang, X. Wang and X. Feng, Desalination, 2016, 386, 67-76.

39 A. Rahimpour, M. Jahanshahi, B. Rajaeian and M. Rahimnejad, Desalination, 2011, 278, 343-353.

40 S. J. Oh, N. Kim and Y. T. Lee, J. Membr. Sci., 2009, 345, 1320.

41 Z.-Q. Huang, K. Chen, S.-N. Li, X.-T. Yin, Z. Zhang and H.-T. Xu, J. Membr. Sci., 2008, 315, 164-171.

42 A. L. Ahmad, M. A. Majid and B. S. Ooi, Desalination, 2011, 268, 266-269.

43 L.-Y. Yu, Z.-L. Xu, H.-M. Shen and H. Yang, J. Membr. Sci., 2009, 337, 257-265.

44 F. Liu, M. R. M. Abed and K. Li, J. Membr. Sci., 2011, 366, 97103.

45 L. Yan, Y. S. Li and C. B. Xiang, Polymer, 2005, 46, 77017706.

46 H. A. Shawky, S.-R. Chae, S. Lin and M. R. Wiesner, Desalination, 2011, 272, 46-50.

47 F. H. Gojny, M. H. G. Wichmann, U. Köpke, B. Fiedler and K. Schulte, Compos. Sci. Technol., 2004, 64, 2363-2371.

48 D. Qian, G. J. Wagner, W. K. Liu, M.-F. Yu and R. S. Ruoff, Appl. Mech. Rev., 2002, 55, 495-533.

49 T. Lin, V. Bajpai, T. Ji and L. Dai, Aust. J. Chem., 2003, 56, 635-651.

50 P. M. Ajayan, O. Stephan, C. Colliex and D. Trauth, Science, 1994, 265, 1212-1214.

51 S. Iijima, Nature, 1991, 354, 56-58.

52 R. Andrews and M. C. Weisenberger, Curr. Opin. Solid State Mater. Sci., 2004, 8, 31-37.

53 P.-C. Ma, N. A. Siddiqui, G. Marom and J.-K. Kim, Composites, Part A, 2010, 41, 1345-1367.

54 D. Heymann, Fullerene Sci. Technol., 1996, 4, 509-515.

55 J.-H. Choi, J. Jegal and W.-N. Kim, J. Membr. Sci., 2006, 284, 406-415. 
56 M. Sianipar, S. H. Kim, C. Min, L. D. Tijing and H. K. Shon, J. Ind. Eng. Chem., 2016, 34, 364-373.

57 Z. Spitalsky, D. Tasis, K. Papagelis and C. Galiotis, Prog. Polym. Sci., 2010, 35, 357-401.

58 S. Daer, J. Kharraz, A. Giwa and S. W. Hasan, Desalination, 2015, 367, 37-48.

59 A. Giwa, N. Akther, V. Dufour and S. W. Hasan, RSC Adv., 2016, 6, 8134-8163.

60 L. Dumée, K. Sears, J. Schütz, N. Finn, M. Duke and S. Gray, Desalination Water Treat., 2010, 17, 72-79.

61 J. Lee, S. Jeong and Z. Liu, Crit. Rev. Environ. Sci. Technol., 2016, 46, 999-1046.

62 R. Das, M. E. Ali, S. B. A. Hamid, S. Ramakhrisna and Z. Z. Chowdhury, Desalination, 2014, 336, 97-109.

63 S. Qiu, L. Wu, X. Pan, L. Zhang, H. Chen and C. Gao, J. Membr. Sci., 2009, 342, 165-172.

64 H. Wu, B. Tang and P. Wu, J. Membr. Sci., 2010, 362, 374383.

65 E. Celik, H. Park, H. Choi and H. Choi, Water Res., 2011, 45, 274-282.

66 E. Celik, L. Liu and H. Choi, Water Res., 2011, 45, 52875294.

67 T. Munegumi, World J. Chem. Educ., 2013, 1, 12-16.

68 X. Yan, D. Pan, Z. Li, B. Zhao, J. Zhang and M. Wu, Mater. Lett., 2010, 64, 1694-1697.

69 V. Vatanpour, S. S. Madaeni, R. Moradian, S. Zinadini and B. Astinchap, Sep. Purif. Technol., 2012, 90, 69-82.

70 M.-J. Han and S.-T. Nam, J. Membr. Sci., 2002, 202, 55-61.

71 K.-W. Lee, B.-K. Seo, S.-T. Nam and M.-J. Han, Desalination, 2003, 159, 289-296.

72 A. L. Ahmad, M. Sarif and S. Ismail, Desalination, 2005, 179, 257-263.

73 V. Vatanpour, S. S. Madaeni, R. Moradian, S. Zinadini and B. Astinchap, J. Membr. Sci., 2011, 375, 284-294.

74 Y. Mansourpanah, S. S. Madaeni, A. Rahimpour, M. Adeli, M. Y. Hashemi and M. R. Moradian, Desalination, 2011, 277, 171-177.

75 P. Daraei, S. S. Madaeni, N. Ghaemi, H. Ahmadi Monfared and M. A. Khadivi, Sep. Purif. Technol., 2013, 104, 32-44.

76 P. Daraei, S. S. Madaeni, N. Ghaemi, M. A. Khadivi, B. Astinchap and R. Moradian, J. Membr. Sci., 2013, 444, 184-191.

77 J. Lee, Y. Ye, A. J. Ward, C. Zhou, V. Chen, A. I. Minett, S. Lee, Z. Liu, S.-R. Chae and J. Shi, Sep. Purif. Technol., 2016, 163, 109-119.

78 Y. Yang, C. Nie, Y. Deng, C. Cheng, C. He, L. Ma and C. Zhao, RSC Adv., 2016, 6, 88265-88276.

79 Q. Zhang, Y. Liu, Y. Su, R. Zhang, L. Fan, Y. Liu, T. Ma and Z. Jiang, RSC Adv., 2016, 6, 35532-35538.

80 A. Khalid, A. A. Al-Juhani, O. C. Al-Hamouz, T. Laoui, Z. Khan and M. A. Atieh, Desalination, 2015, 367, 134-144.

81 G. Zeng, Y. He, Z. Yu, X. Yang, R. Yang and L. Zhang, J. Chem. Technol. Biotechnol., 2016, 91, 2322-2330.

82 H. Zarrabi, M. E. Yekavalangi, V. Vatanpour, A. Shockravi and M. Safarpour, Desalination, 2016, 394, 83-90.

83 S.-M. Xue, Z.-L. Xu, Y.-J. Tang and C.-H. Ji, ACS Appl. Mater. Interfaces, 2016, 8, 19135-19144.
84 C. Wang, H. Wu, F. Qu, H. Liang, X. Niu and G. Li, J. Appl. Polym. Sci., 2016, 133, 43417.

85 Y. Zhao, Z. Xu, M. Shan, C. Min, B. Zhou, Y. Li, B. Li, L. Liu and X. Qian, Sep. Purif. Technol., 2013, 103, 78-83.

86 N. Phao, E. N. Nxumalo, B. B. Mamba and S. D. Mhlanga, Phys. Chem. Earth, 2013, 66, 148-156.

87 M. Son, H. Choi, L. Liu, E. Celik, H. Park and H. Choi, Chem. Eng. J., 2015, 266, 376-384.

88 M.-B. Wu, Y. Lv, H.-C. Yang, L.-F. Liu, X. Zhang and Z.-K. Xu, J. Membr. Sci., 2016, 515, 238-244.

89 M. Norouzi, M. Pakizeh and M. Namvar-Mahboub, Desalination Water Treat., 2016, 57, 24778-24787.

90 S. Majeed, D. Fierro, K. Buhr, J. Wind, B. Du, A. Boschettide-Fierro and V. Abetz, J. Membr. Sci., 2012, 403-404, 101109.

91 A. Rahimpour, M. Jahanshahi, S. Khalili, A. Mollahosseini, A. Zirepour and B. Rajaeian, Desalination, 2012, 286, 99107.

92 G. Vuković, A. Marinković, M. Obradović, V. Radmilović, M. Čolić, R. Aleksić and P. S. Uskoković, Appl. Surf. Sci., 2009, 255, 8067-8075.

93 J. Shen, W. Huang, L. Wu, Y. Hu and M. Ye, Mater. Sci. Eng., A, 2007, 464, 151-156.

94 J. Kathi, K.-Y. Rhee and J. H. Lee, Composites, Part A, 2009, 40, 800-809.

95 T.-H. Bae and T.-M. Tak, J. Membr. Sci., 2005, 249, 1-8.

96 A. Jitianu, T. Cacciaguerra, R. Benoit, S. Delpeux, F. Béguin and S. Bonnamy, Carbon, 2004, 42, 1147-1151.

97 H. Wang, X. Quan, H. Yu and S. Chen, Carbon, 2008, 46, 1126-1132.

98 S. W. Phang, M. Tadokoro, J. Watanabe and N. Kuramoto, Synth. Met., 2008, 158, 251-258.

99 B. Fei, B. Qian, Z. Yang, R. Wang, W. C. Liu, C. L. Mak and J. H. Xin, Carbon, 2008, 46, 1795-1797.

100 H. Lee, S. M. Dellatore, W. M. Miller and P. B. Messersmith, Science, 2007, 318, 426-430.

101 B. Yu, J. Liu, S. Liu and F. Zhou, Chem. Commun., 2010, 46, 5900-5902.

102 E. Kaxiras, A. Tsolakidis, G. Zonios and S. Meng, Phys. Rev. Lett., 2006, 97, 218102.

103 A. Postma, Y. Yan, Y. Wang, A. N. Zelikin, E. Tjipto and F. Caruso, Chem. Mater., 2009, 21, 3042-3044.

104 B. Yu, D. A. Wang, Q. Ye, F. Zhou and W. Liu, Chem. Commun., 2009, 6789-6791.

105 S. Kang and M. Elimelech, Langmuir, 2009, 25, 9656-9659.

106 A. Bourmaud, J. Riviere, A. Le Duigou, G. Raj and C. Baley, Polym. Test., 2009, 28, 668-672.

107 L. A. N. El-Din, A. El-Gendi, N. Ismail, K. A. Abed and A. I. Ahmed, J. Ind. Eng. Chem., 2015, 26, 259-264.

108 M. R. N. Esfahani, J. Coupland and S. Marimuthu, Int. J. Adv. Des. Manuf. Technol., 2015, 80, 1449-1456.

109 K. Balasubramanian and M. Burghard, Small, 2005, 1, 180192.

110 H. Kuzmany, A. Kukovecz, F. Simon, M. Holzweber, C. Kramberger and T. Pichler, Synth. Met., 2004, 141, 113122.

111 A. Hirsch, Angew. Chem., Int. Ed., 2002, 41, 1853-1859. 
112 W. Duan, A. Ronen, S. Walker and D. Jassby, ACS Appl. Mater. Interfaces, 2016, 8, 22574-22584.

113 W.-F. Chan, E. Marand and S. M. Martin, J. Membr. Sci., 2016, 509, 125-137.

114 M. Amirilargani, A. Ghadimi, M. A. Tofighy and T. Mohammadi, J. Membr. Sci., 2013, 447, 315-324.

115 M. Majumder, N. Chopra and B. J. Hinds, J. Am. Chem. Soc., 2005, 127, 9062-9070.

116 C. H. Ahn, Y. Baek, C. Lee, S. O. Kim, S. Kim, S. Lee, S.-H. Kim, S. S. Bae, J. Park and J. Yoon, J. Ind. Eng. Chem., 2012, 18, 1551-1559.

117 B. J. Hinds, N. Chopra, T. Rantell, R. Andrews, V. Gavalas and L. G. Bachas, Science, 2004, 303, 62-65.

118 M. Mulder, Basic Principle of Membrane Technology, Kluwer Academic Publisher, Netherlands, 1996.

119 Y. C. Choi, Y. M. Shin, Y. H. Lee and B. S. Lee, Appl. Phys. Lett., 2000, 76, 2367-2369.

120 B. Corry, Energy Environ. Sci., 2011, 4, 751-759.

121 S. Li, G. Liao, Z. Liu, Y. Pan, Q. Wu, Y. Weng, X. Zhang, Z. Yang and O. K. C. Tsui, J. Mater. Chem. A, 2014, 2, 12171-12176.

122 J. K. Holt, A. Noy, T. Huser, D. Eaglesham and O. Bakajin, Nano Lett., 2004, 4, 2245-2250.

123 J. K. Holt, H. G. Park, Y. Wang, M. Stadermann, A. B. Artyukhin, C. P. Grigoropoulos, A. Noy and O. Bakajin, Science, 2006, 312, 1034-1037.

124 W. Mi, Y. S. Lin and Y. Li, J. Membr. Sci., 2007, 304, 1-7.

125 F. Du, L. Qu, Z. Xia, L. Feng and L. Dai, Langmuir, 2011, 27, 8437-8443.

126 I. A. Smallwood, Handbook of organic solvent properties, John Wiley \& Sons Inc., New York, 1996.

127 W. Chen, L. Duan and D. Zhu, Environ. Sci. Technol., 2007, 41, 8295-8300.

128 C. Sendner, D. Horinek, L. Bocquet and R. R. Netz, Langmuir, 2009, 25, 10768-10781.

129 Y. Y. Huang, S. V. Ahir and E. M. Terentjev, Phys. Rev. B: Condens. Matter Mater. Phys., 2006, 73, 125422.

130 B. B. Khatua, D. J. Lee, H. Y. Kim and J. K. Kim, Macromolecules, 2004, 37, 2454-2459.

131 O. V. Kharissova, B. I. Kharisov and E. G. d. C. Ortiz, $R S C$ Adv., 2013, 3, 24812-24852.

132 Z. Yu, G. Zeng, Y. Pan, L. Lv, H. Min, L. Zhang and Y. He, $R S C A d v ., 2015$, 5, 75998-76006.

133 Y. Yuan and T. R. Lee, in Surface Science Techniques, ed. G. Bracco and B. Holst, Springer Berlin Heidelberg, Berlin, Heidelberg, 2013, pp. 3-34.

134 M. R. Esfahani, J. L. Tyler, H. A. Stretz and M. J. M. Wells, Desalination, 2015, 372, 47-56.

135 L. Dumée, V. Germain, K. Sears, J. Schütz, N. Finn, M. Duke, S. Cerneaux, D. Cornu and S. Gray, J. Membr. Sci., 2011, 376, 241-246.

136 S. Roy, M. Bhadra and S. Mitra, Sep. Purif. Technol., 2014, 136, 58-65.

137 M. Bhadra, S. Roy and S. Mitra, Sep. Purif. Technol., 2016, 161, 136-143.
138 S. Morales-Torres, T. L. S. Silva, L. M. Pastrana-Martínez, A. T. S. C. Brandão, J. L. Figueiredo and A. M. T. Silva, Phys. Chem. Chem. Phys., 2014, 16, 12237-12250.

139 A. Kyoungjin An, E.-J. Lee, J. Guo, S. Jeong, J.-G. Lee and N. Ghaffour, Sci. Rep., 2017, 7, 41562.

140 M. Nilsson, G. Trägårdh and K. Östergren, J. Membr. Sci., 2008, 312, 97-106.

141 J. M. M. Peeters, J. P. Boom, M. H. V Mulder and H. Strathmann, J. Membr. Sci., 1998, 145, 199-209.

142 I. H. Huisman, P. Prádanos and A. Hernández, J. Membr. Sci., 2000, 179, 79-90.

143 A. G. Fane, C. J. D. Fell and A. Suki, J. Membr. Sci., 1983, 16, 195-210.

144 A. G. Fane, C. J. D. Fell and A. G. Waters, J. Membr. Sci., 1983, 16, 211-224.

145 S. Kar, R. C. Bindal and P. K. Tewari, Nano Today, 2012, 7, 385-389.

146 J. H. Walther, K. Ritos, E. R. Cruz-Chu, C. M. Megaridis and P. Koumoutsakos, Nano Lett., 2013, 13, 1910-1914.

147 B. Corry, J. Phys. Chem. B, 2008, 112, 1427-1434.

148 S. Joseph and N. R. Aluru, Nano Lett., 2008, 8, 452-458.

149 J. Zhang, Z. Xu, W. Mai, C. Min, B. Zhou, M. Shan, Y. Li, C. Yang, Z. Wang and X. Qian, J. Mater. Chem. A, 2013, 1, 3101-3111.

150 M. N. Z. Abidin, P. S. Goh, A. F. Ismail, M. H. D. Othman, H. Hasbullah, N. Said, S. H. S. A. Kadir, F. Kamal, M. S. Abdullah and B. C. Ng, Mater. Sci. Eng., C, 2016, 68, 540-550.

151 N. Mehwish, A. Kausar and M. Siddiq, Polym.-Plast. Technol. Eng., 2015, 54, 474-483.

152 K. Yokwana, N. Gumbi, F. Adams, S. Mhlanga, E. Nxumalo and B. Mamba, J. Appl. Polym. Sci., 2015, 132, 41835.

153 H. Choi, S. H. Yoon, M. Son, E. Celik, H. Park and H. Choi, Desalination Water Treat., 2016, 57, 7545-7554.

154 M. A. Tofighy, Y. Shirazi, T. Mohammadi and A. Pak, Chem. Eng. J., 2011, 168, 1064-1072.

155 M. Bhadra, S. Roy and S. Mitra, Sep. Purif. Technol., 2013, 120, 373-377.

156 T. L. S. Silva, S. Morales-Torres, J. L. Figueiredo and A. M. T. Silva, Desalination, 2015, 357, 233-245.

157 M. Son, V. Novotny and H. Choi, Desalination Water Treat., 2016, 57, 26670-26679.

158 T. Wang, J. Shen, L. Wu and B. Van der Bruggen, J. Membr. Sci., 2014, 466, 338-347.

159 M. Amirilargani, M. A. Tofighy, T. Mohammadi and B. Sadatnia, Ind. Eng. Chem. Res., 2014, 53, 12819-12829.

160 M. Amirilargani, A. Ghadimi, M. A. Tofighy and T. Mohammadi, J. Membr. Sci., 2013, 447, 315-324.

161 J.-H. Choi, J. Jegal, W.-N. Kim and H.-S. Choi, J. Appl. Polym. Sci., 2009, 111, 2186-2193.

162 S. Y. Hu, Y. Zhang, D. Lawless and X. Feng, J. Membr. Sci., 2012, 417-418, 34-44.

163 Y. T. Ong, A. L. Ahmad, S. Hussein, S. Zein, K. Sudesh and S. H. Tan, Sep. Purif. Technol., 2011, 76, 419-427.

164 Q. W. Yeang, S. H. S. Zein, A. B. Sulong and S. H. Tan, Sep. Purif. Technol., 2013, 107, 252-263. 
165 F. Peng, F. Pan, H. Sun, L. Lu and Z. Jiang, J. Membr. Sci., 2007, 300, 13-19.

166 C. Iamsamai, A. Soottitantawat, U. Ruktanonchai, S. Hannongbua and S. T. Dubas, Carbon, 2011, 49, 2039-2045.

167 P. T. Hammond, Curr. Opin. Colloid Interface Sci., 1999, 4, 430-442.
168 P. Bertrand, A. Jonas, A. Laschewsky and R. Legras, Macromol. Rapid Commun., 2000, 21, 319-348.

169 Q. Li, D. Yang, J. Shi, X. Xu, S. Yan and Q. Liu, Desalination, 2016, 379, 164-171.

170 P. Nednoor, V. G. Gavalas, N. Chopra, B. J. Hinds and L. G. Bachas, J. Mater. Chem., 2007, 17, 1755-1757. 